\title{
Multiaxial and Thermomechanical Fatigue of Materials: A Historical Perspective and Some Future Challenges
}

\author{
Sreeramesh Kalluri \\ Ohio Aerospace Institute \\ NASA Glenn Research Center \\ Brook Park, Ohio
}

Swedlow Memorial Lecture

$13^{\text {th }}$ International ASTM/ESIS Symposium on Fatigue and Fracture Mechanics (39th ASTM National Symposium on Fatigue and Fracture Mechanics)

November 13-15, 2013, Jacksonville, Florida 


\section{Rationale for Multiaxial and Thermomechanical Fatigue}

- Structural materials used in engineering applications routinely subjected to repetitive mechanical loads in multiple directions under non-isothermal conditions

- Over past few decades, several multiaxial fatigue life estimation models (stress- and strain-based) developed for isothermal conditions

- Historically, numerous fatigue life prediction models also developed for thermomechanical fatigue (TMF) life prediction, predominantly for uniaxial mechanical loading conditions

- Realistic structural components encounter multiaxial loads and non-isothermal loading conditions, which increase potential for interaction of damage modes. A need exists for mechanical testing and development $\&$ verification of life prediction models under such conditions. 


\section{Typical Gas Turbine Engine Hot Section Components}
Combustor
Vane
Turbine blade
Turbine disk
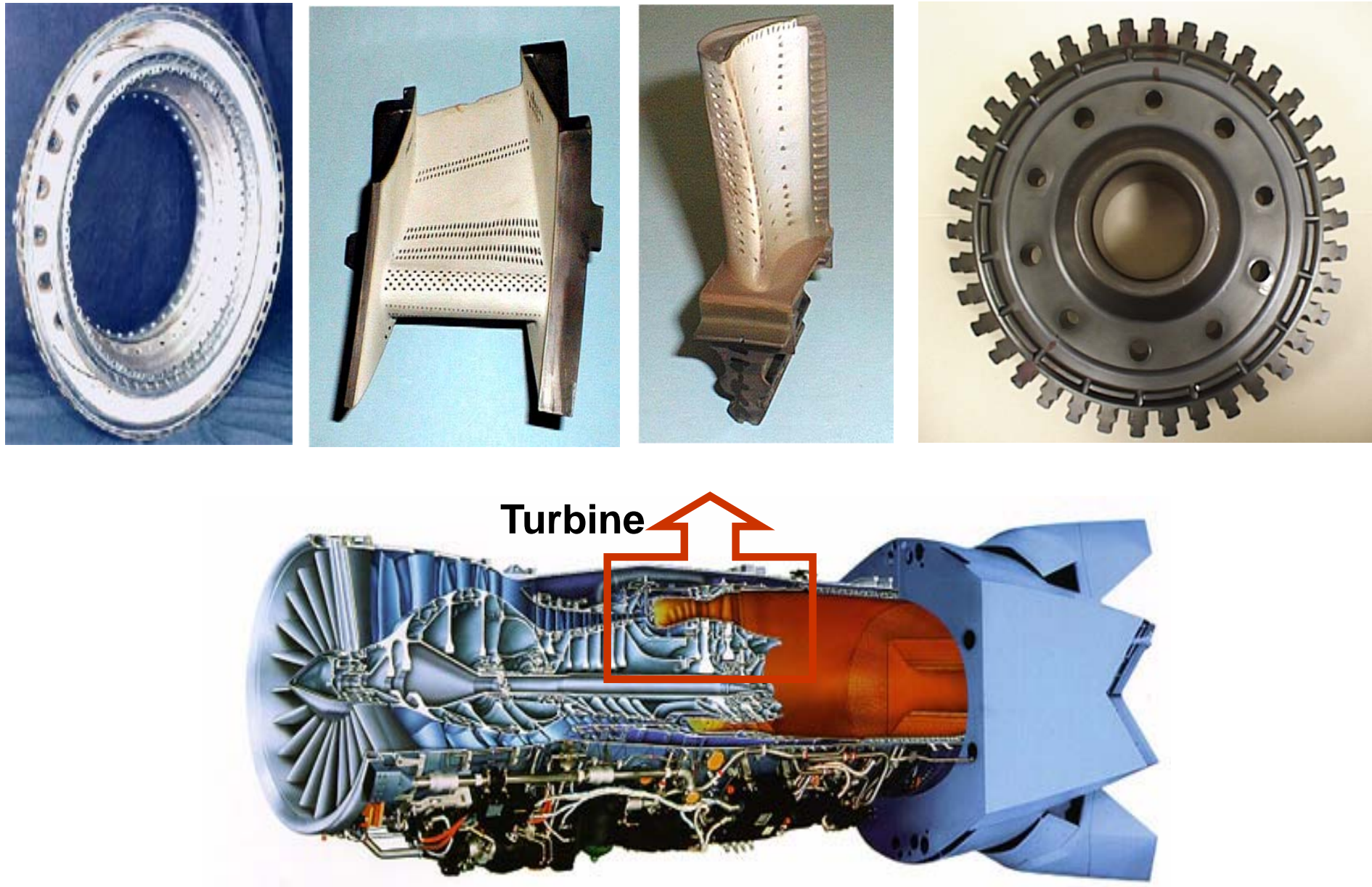


\section{PM Processed Nickel-Based Superalloy Disk}

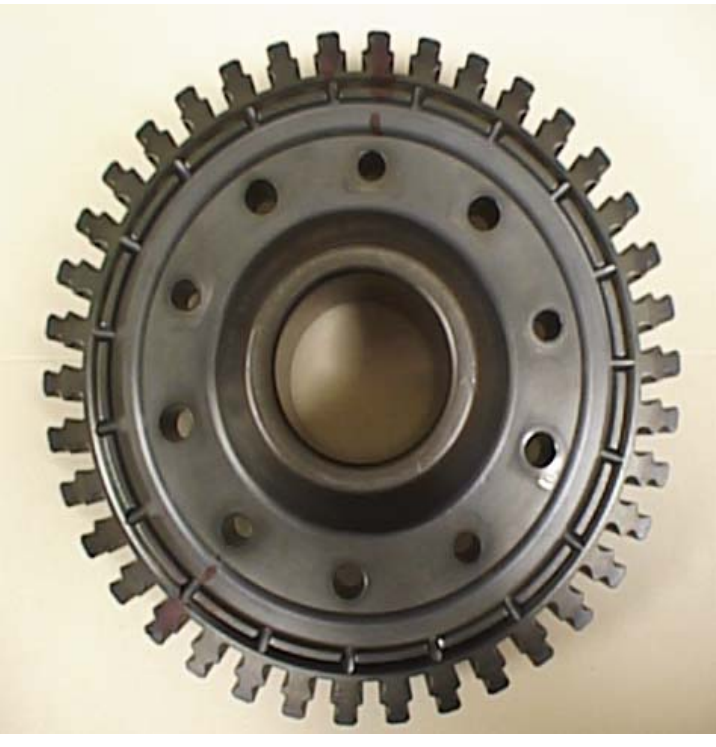

Turbine disk subjected to thermal cycles and multiaxial loads during start-ups and shutdowns

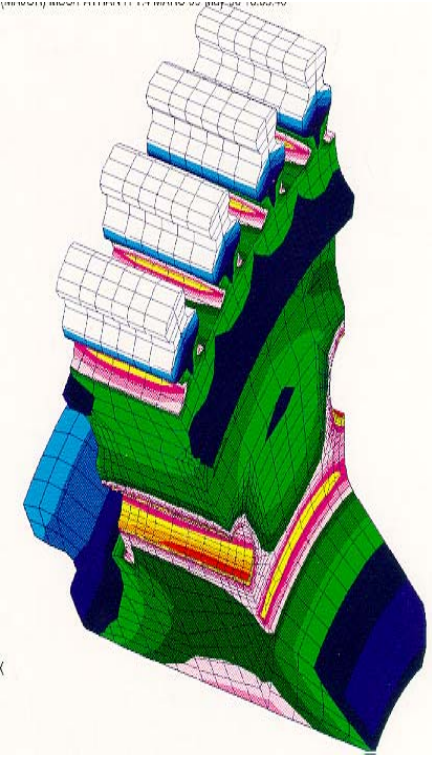

Finite element analysis revealing stress concentrations at several locations including the holes

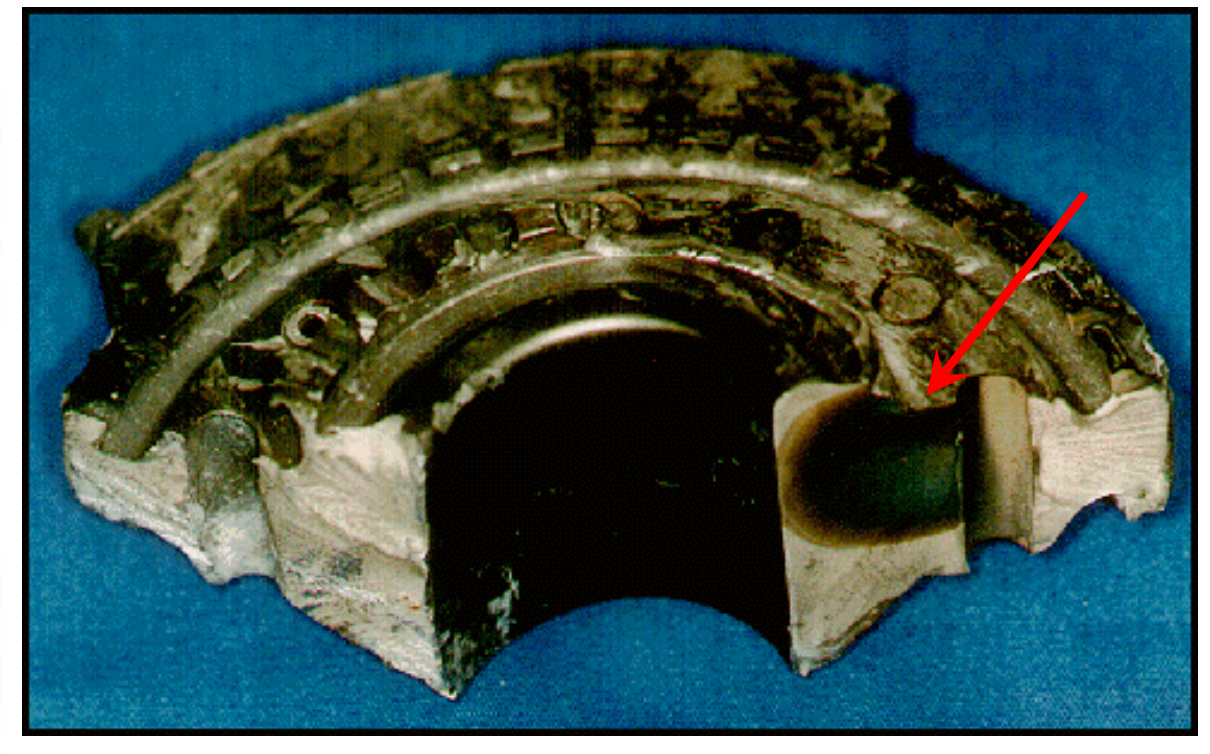

Uncontained disk burst Crack initiated from corner of the hole

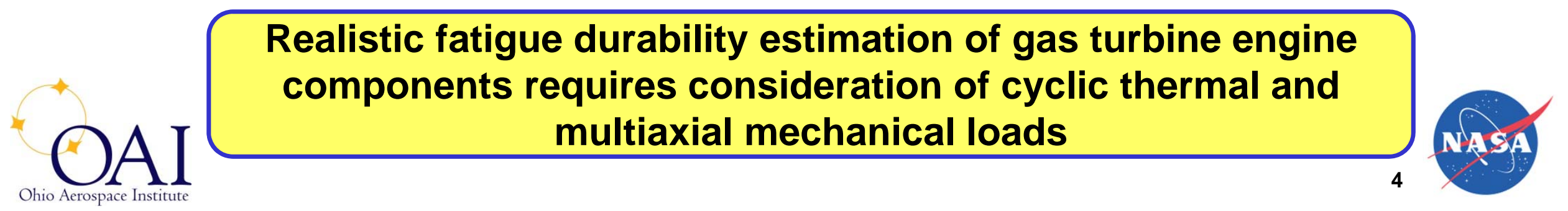




\section{Multiaxial and Thermomechanical Fatigue}

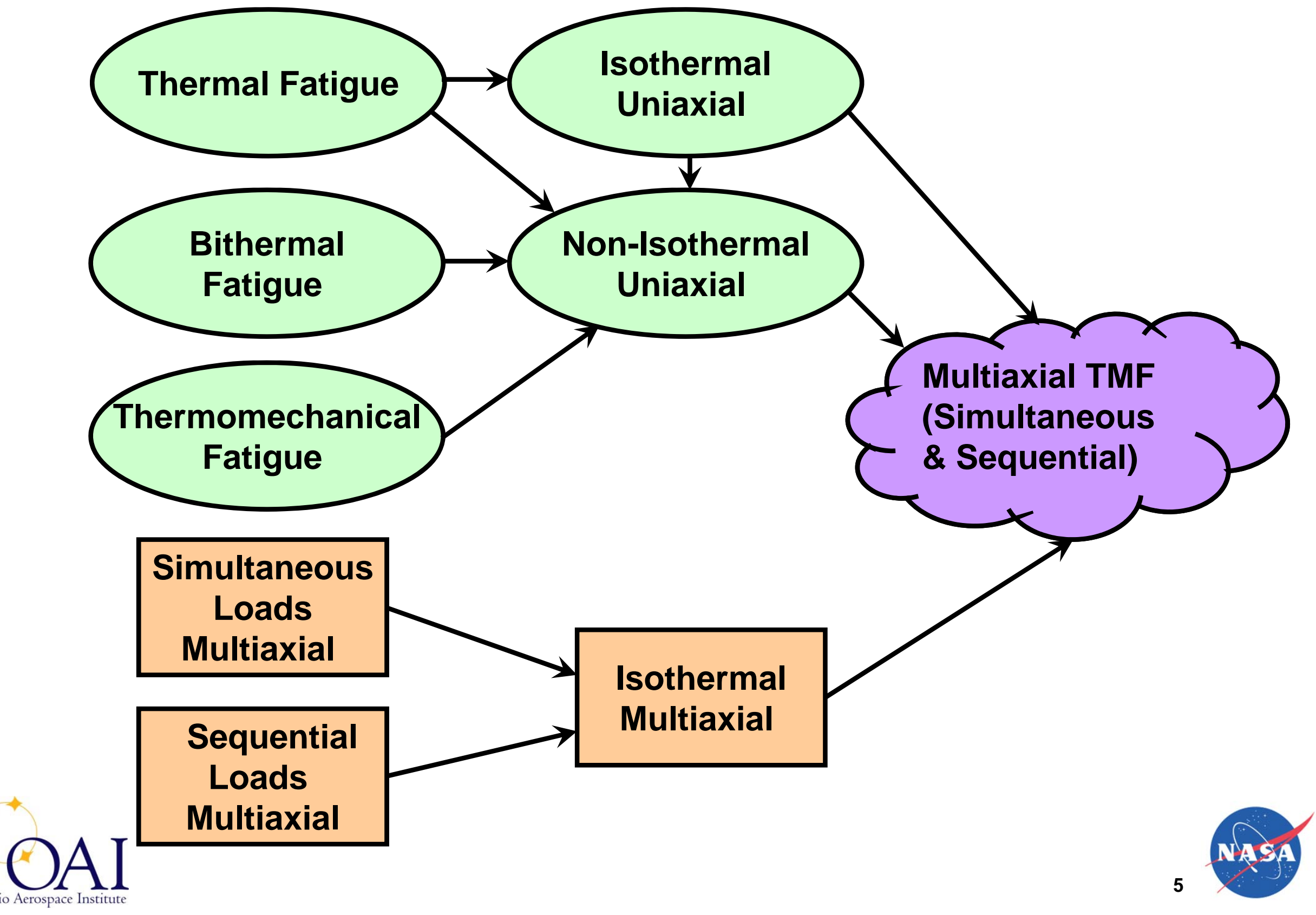




\section{Multiaxial and Thermomechanical Fatigue - Scope}

- Materials (metallic alloys, polymers, ceramics, composites, and materials with coatings)

- Structural alloys for aerospace applications (uncoated)

- Fatigue crack initiation and fatigue crack growth

- Fatigue crack initiation

- Low-cycle versus high-cycle fatigue

- Low-cycle fatigue (primarily strain-based approaches)

- Deterministic versus probabilistic fatigue life estimation

- Deterministic fatigue life estimation

- Multiaxial, thermomechanical fatigue - numerous possibilities

- Some selected examples

- Future challenges in multiaxial thermomechanical fatigue

- Cumulative fatigue, subcomponents, coatings, composite \& functionally graded materials, and residual stresses 


\section{Multiaxial and Thermomechanical Fatigue}

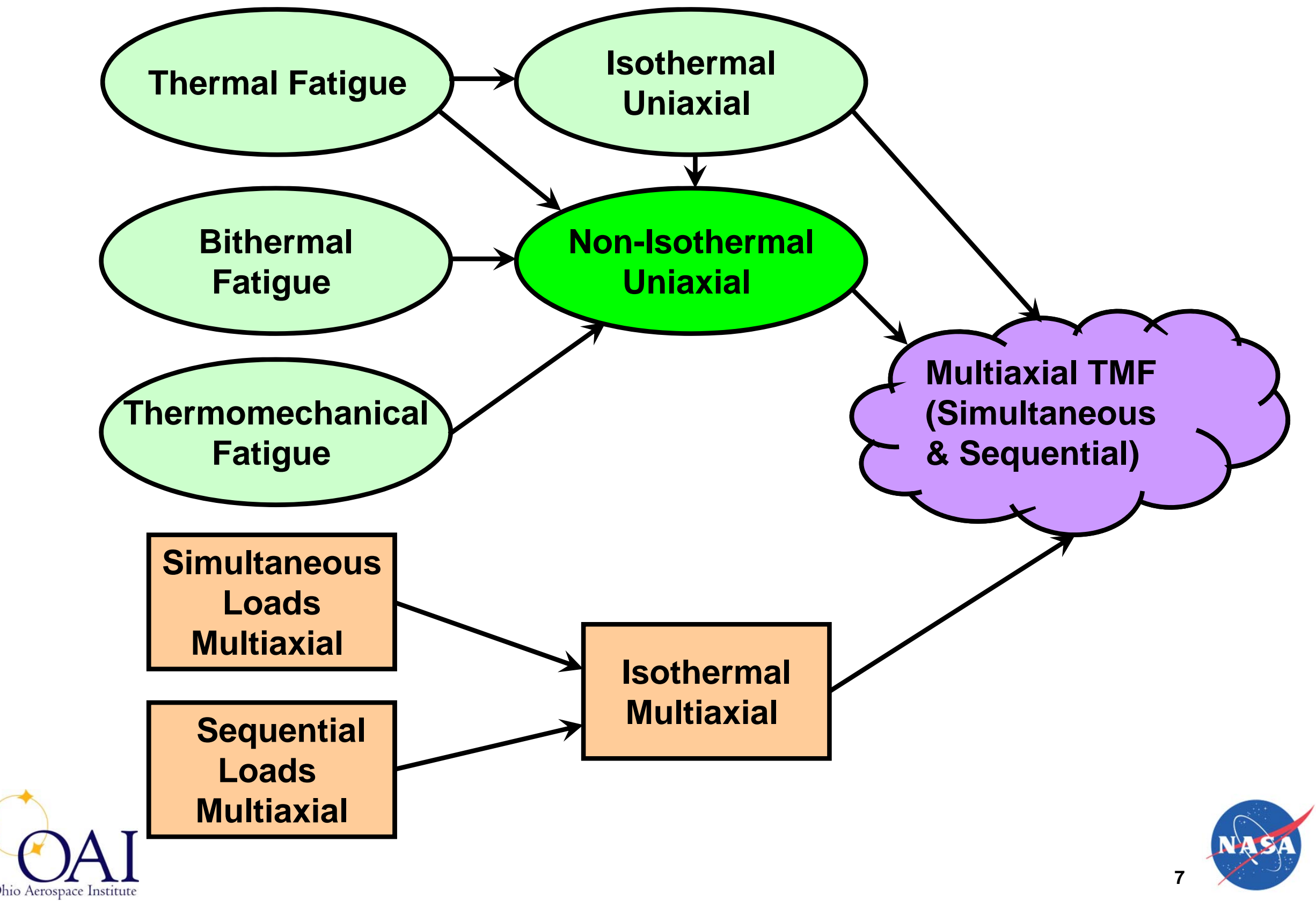




\section{Multiaxial and Thermomechanical Fatigue}

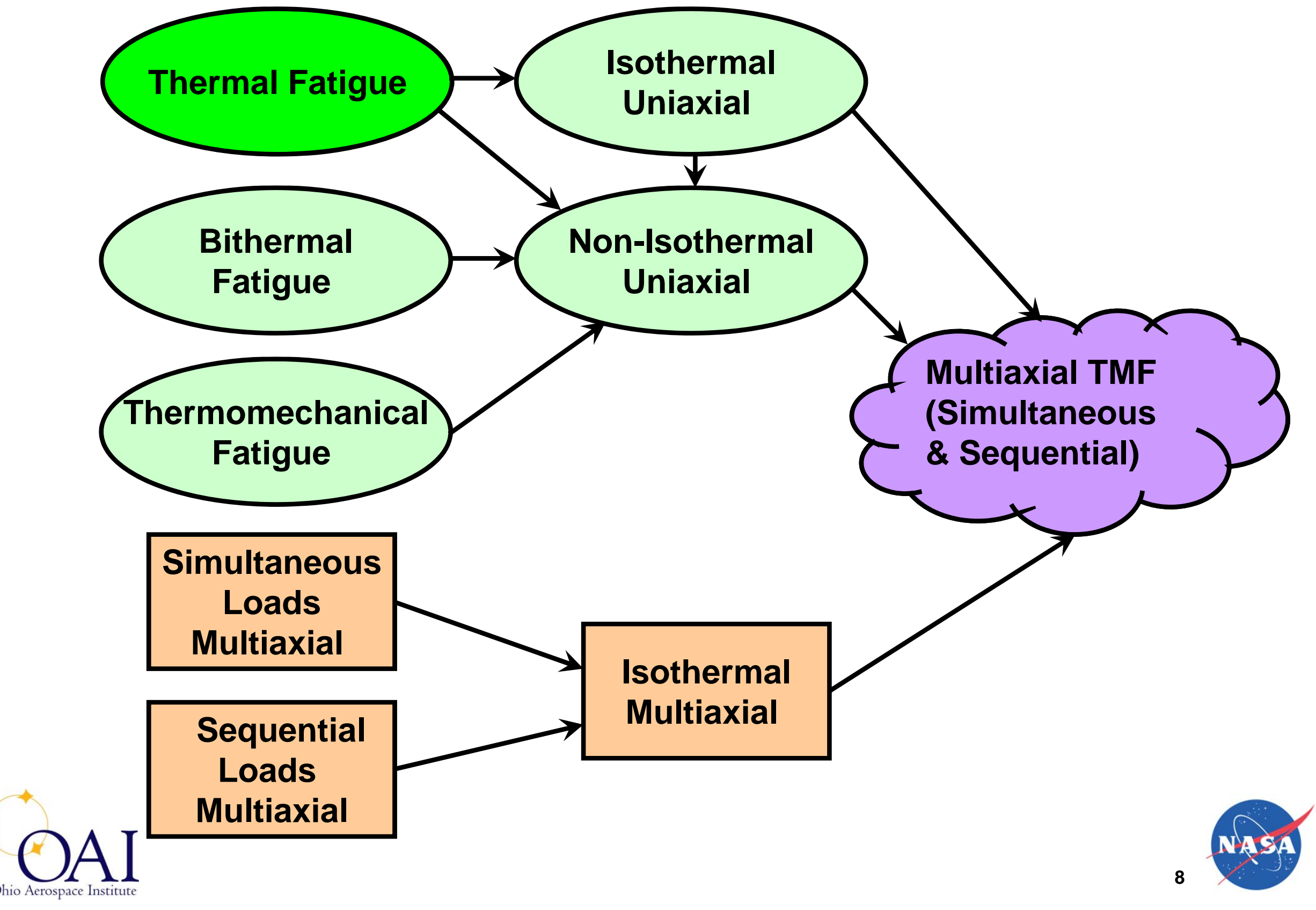




\section{Thermal Fatigue - Experiments and Life Prediction}

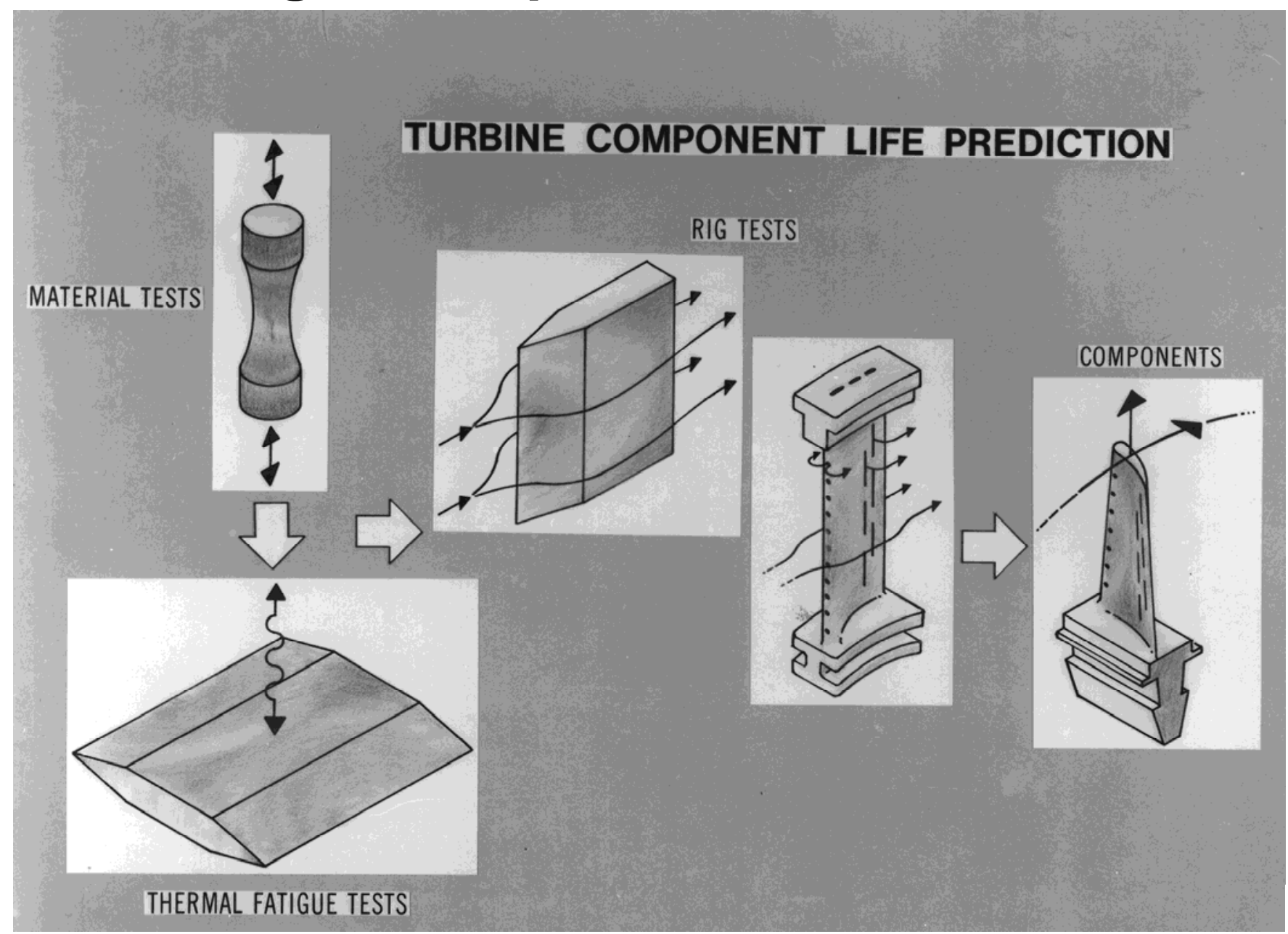

combustion beds to evaluate thermal low-cycle fatigue 


\section{Thermal Fatigue - Inelastic Strains and Cracking}

THERMAL FATIGUE CRACKS IN INIOO

SIMULATED TURBINE BLADES

UNCOATED, 6003 3-MIN CYCLES, $350 \mathrm{~K} \rightleftarrows 1280 \mathrm{~K}$

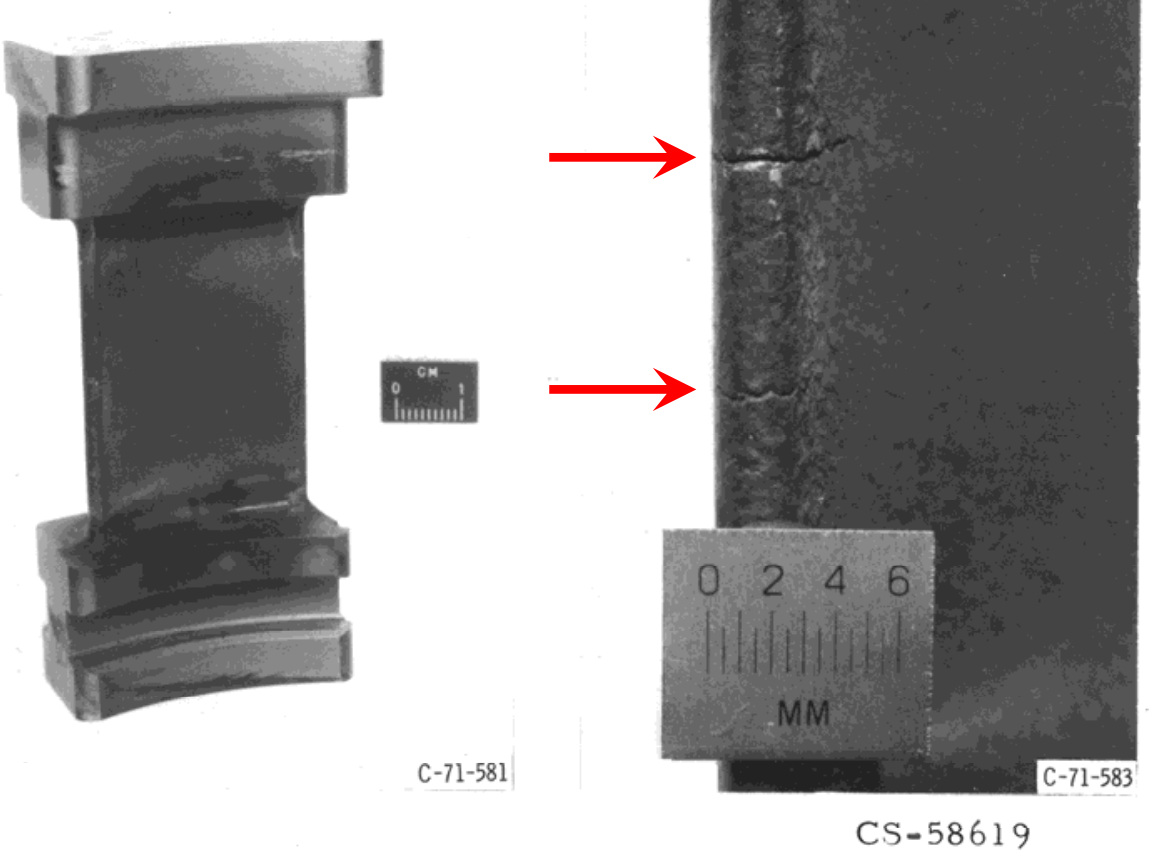

- Salient features

- Thermal cycling with an inherent constraint on deformation

- Typically limited or no externally imposed loads

- Mainly deformation controlled

inelastic strains, which lead to fatigue cracks 


\section{Thermal Fatigue: Life Estimation Model}

- Thermal fatigue

- Inelastic strain range developed during the thermal cycle dictates the fatigue life

- Manson (1953) and Coffin (1954) working independently developed a power law fatigue life relation

\section{Manson-Coffin Equation: $\quad \Delta \varepsilon_{\text {in }}=\mathrm{C}\left(\mathrm{N}_{\mathrm{f}}\right)^{\mathrm{c}}$}

Where, $\Delta \varepsilon_{\text {in }}$ is inelastic strain range, $\mathbf{N}_{\mathbf{f}}$ is fatigue life, $\mathbf{C}$ is the Coefficient, And $c$ is the exponent

References:

[1] Halford, G. R., "Low-Cycle Thermal Fatigue," Thermal Stresses II, R. B. Hetnarsky (Ed.), Elsevier Science Publishers B.V., 1987, pp. 330-428.

[2] Sehitoglu, H., "Thermal and Thermomechanical Fatigue of Structural Alloys," Fatigue and Fracture, ASM Handbook, Volume 19, 1996, pp. 527-556. 


\section{Multiaxial and Thermomechanical Fatigue}

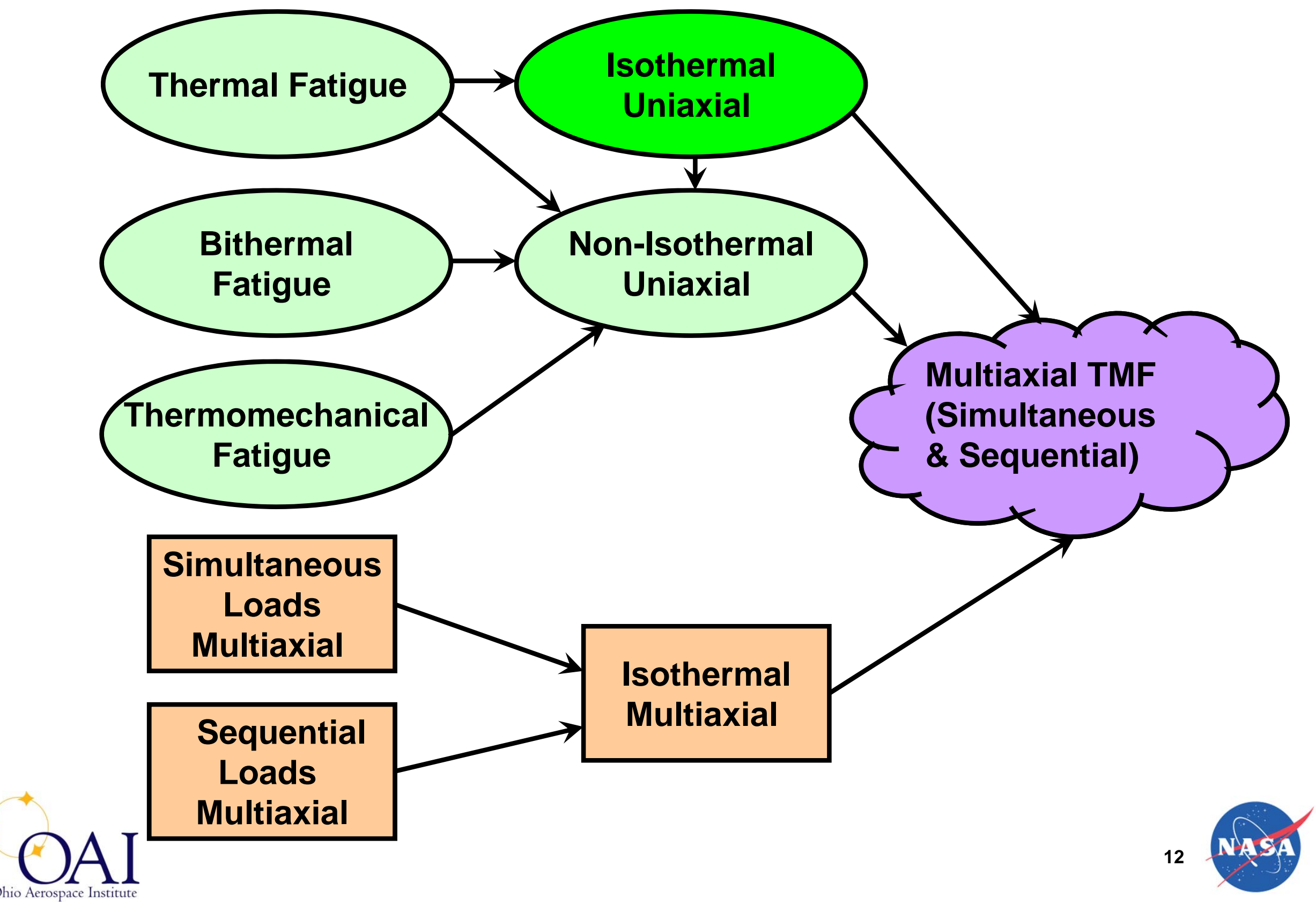


Isothermal Uniaxial Fatigue - Schematic and Life Relations
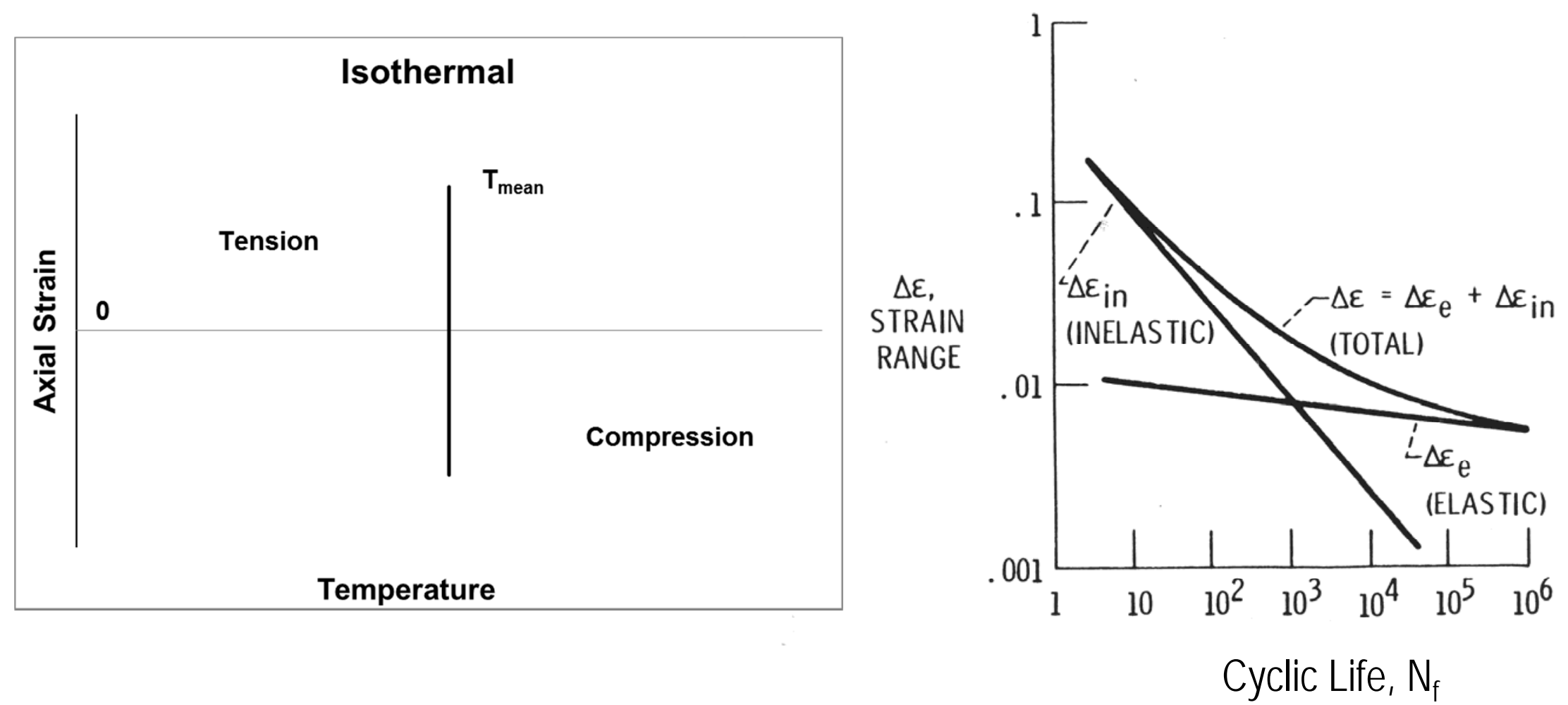

Manson-Coffin-Basquin relation for deterministic, isothermal low-cycle fatigue life estimation 


\section{Isothermal Uniaxial Creep-Fatigue: A Phenomenological Model for Cyclic Life Estimation}

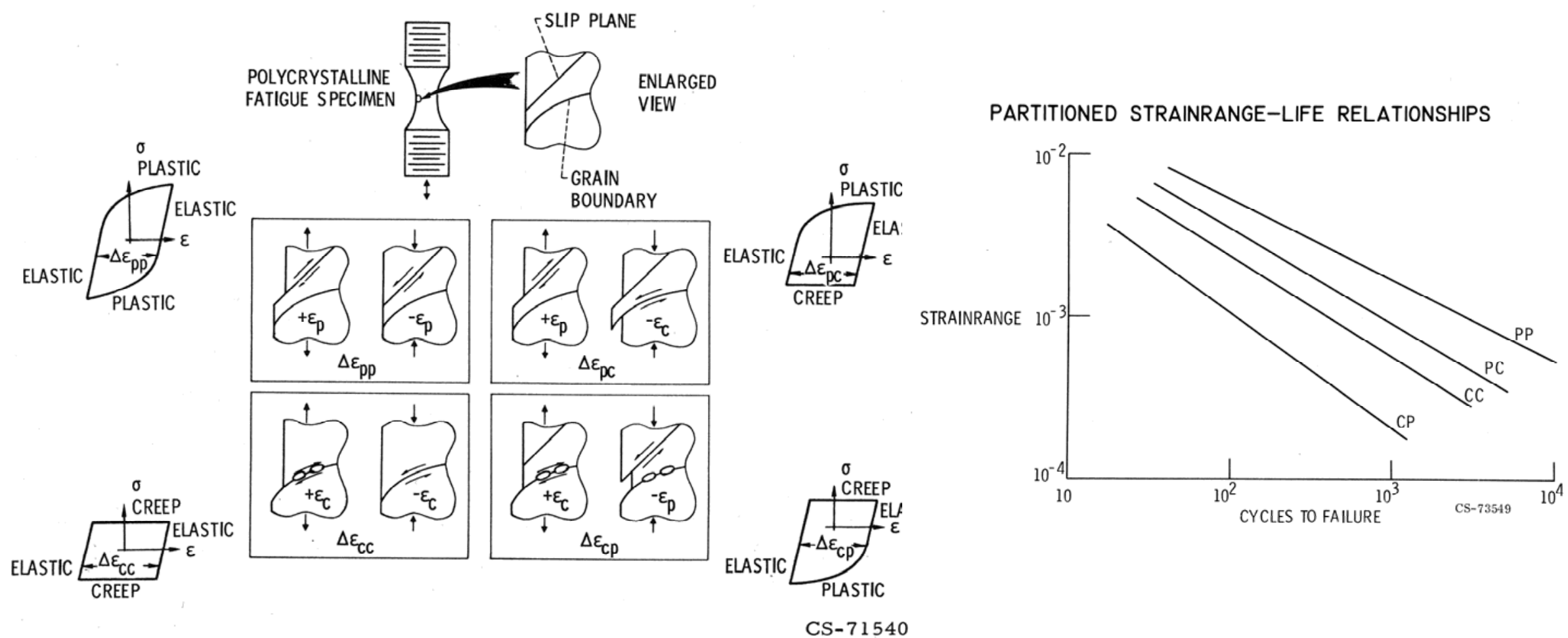

Strain Range Partitioning (SRP) Model: Damage from different deformation modes combined with Interaction Damage Rule 


\section{Multiaxial and Thermomechanical Fatigue}






\section{Bithermal Uniaxial Fatigue: Schematics and Salient Features}
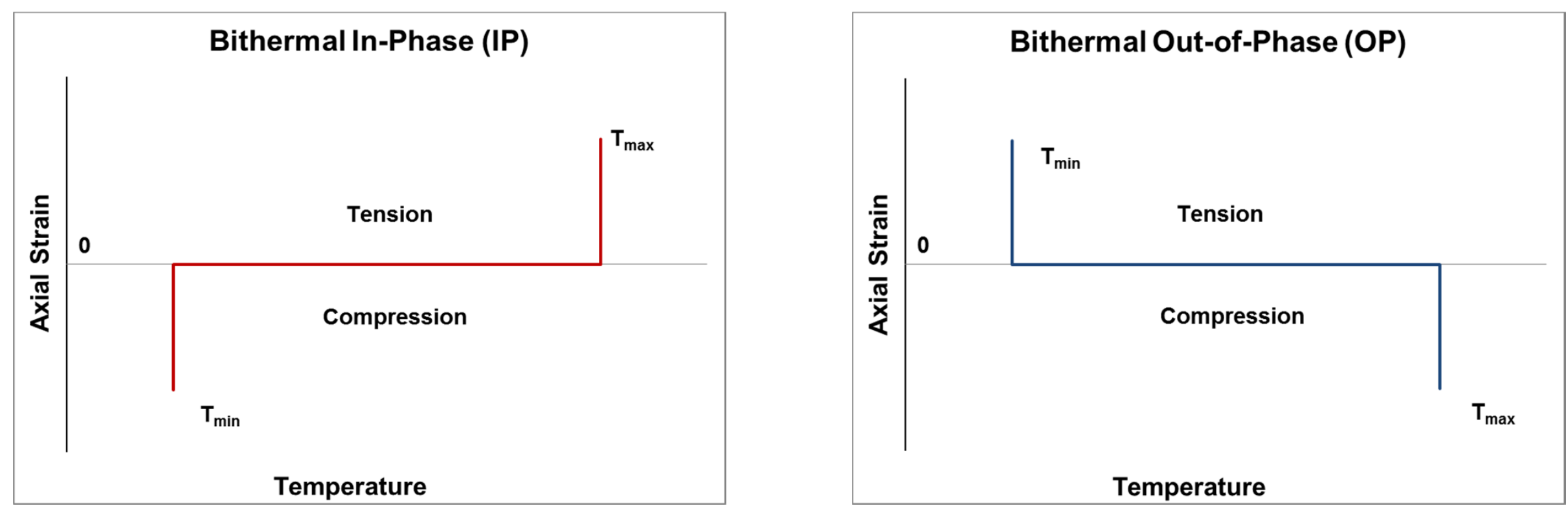

- Salient features

- Thermal cycling at two temperatures with externally imposed loads

- Free thermal expansion allowed during temperature changes

- Effectively two isothermal segments of loading in tension and compression

- Load controlled with limits on deformation 


\section{Bithermal Uniaxial Creep-Fatigue: Schematic Hysteresis Loops}
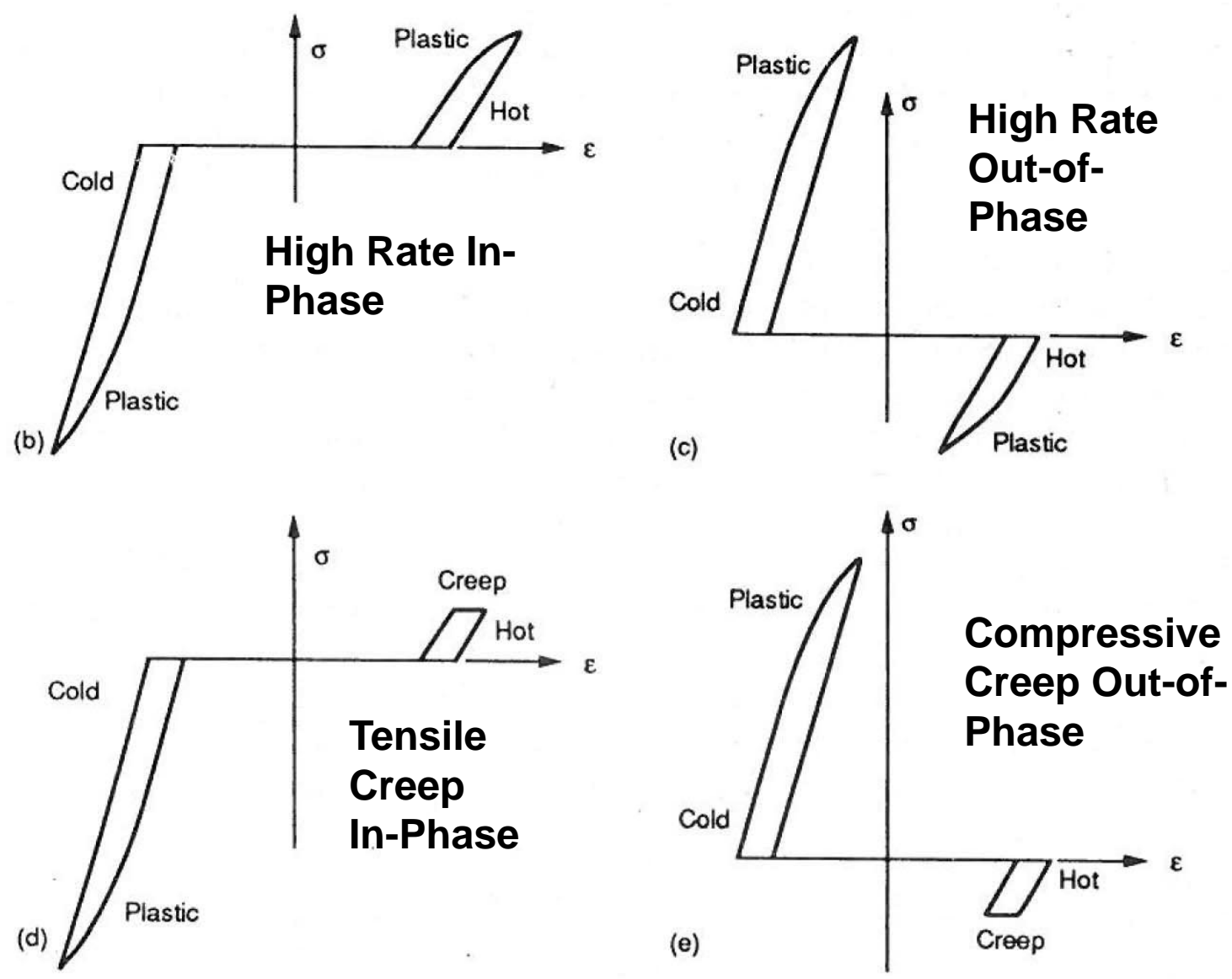

References: Halford et al., ASTM STP 942, 1987 and Halford et al., ASTM STP 1122, 1991

Originally conceived to impose creep in a short time and later viewed as a link between isothermal fatigue and TMF 


\section{Multiaxial and Thermomechanical Fatigue}

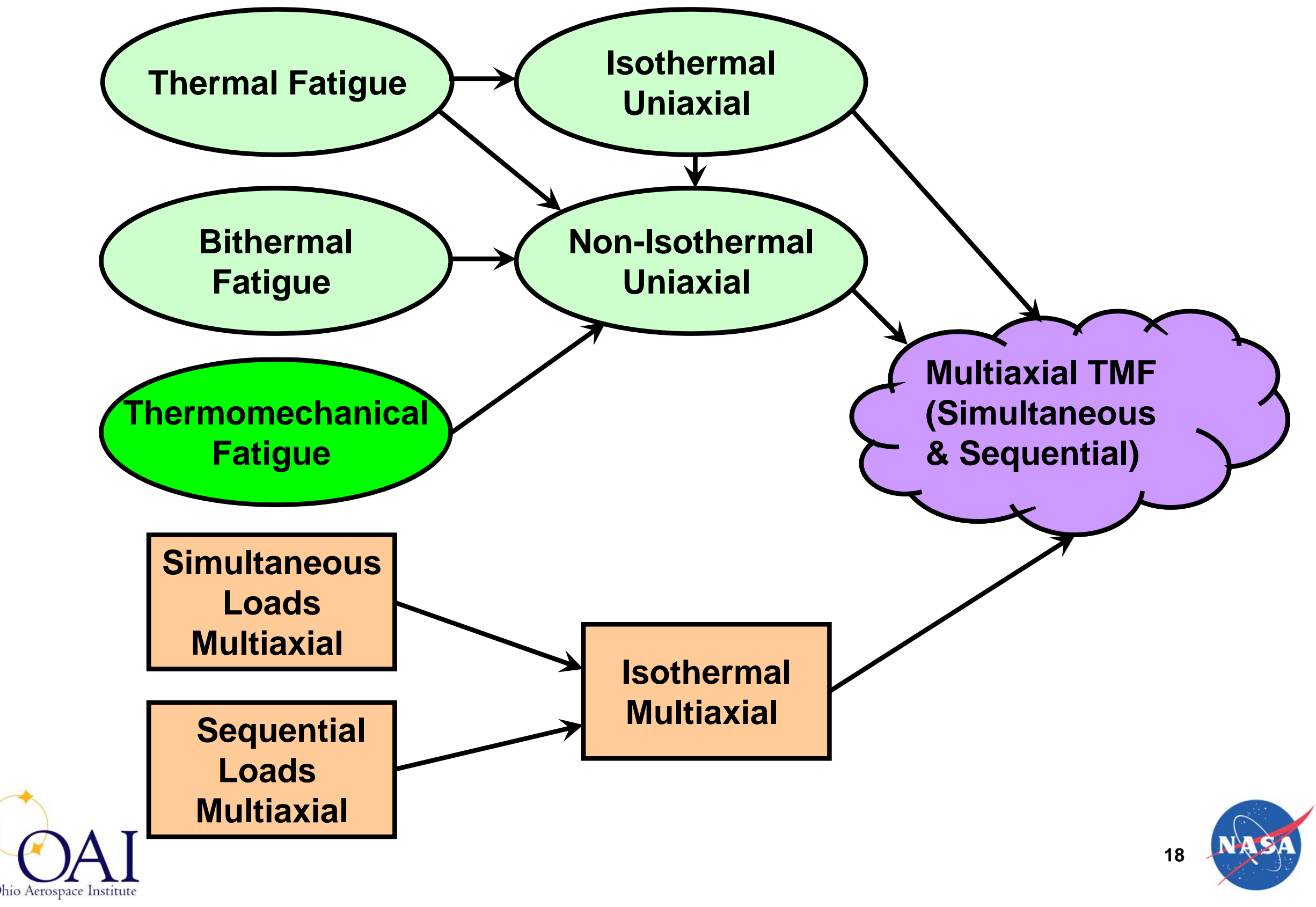




\section{Thermomechanical Uniaxial Fatigue: Schematics and Salient Features}
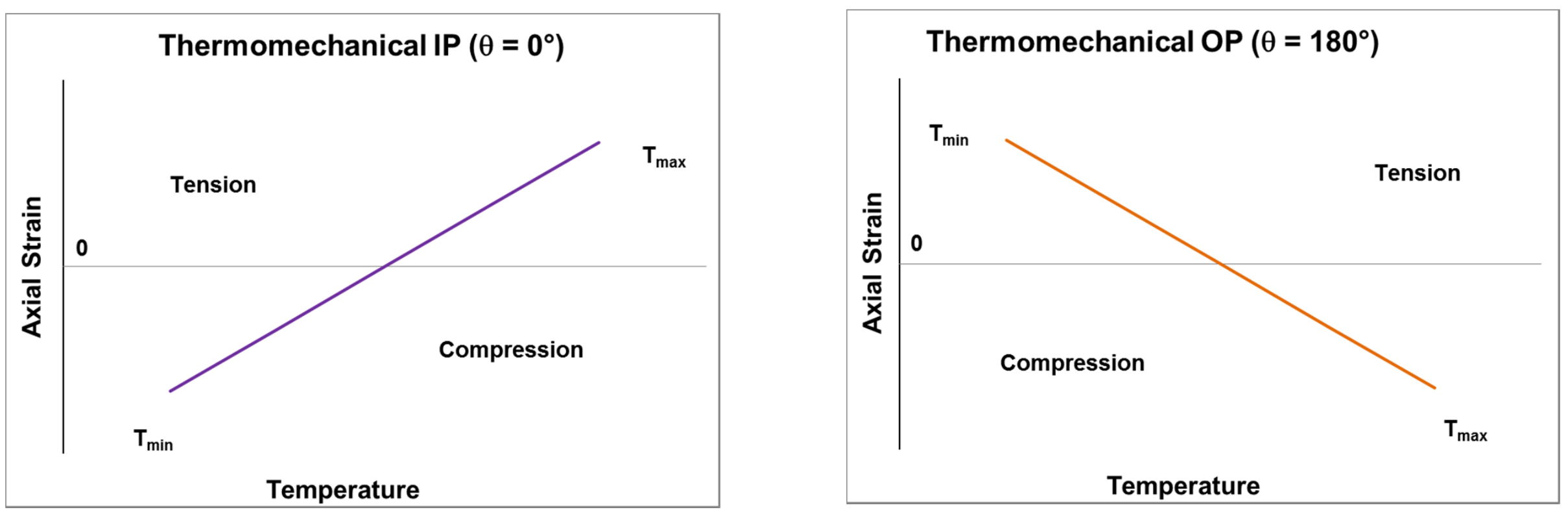

- Salient Features

- Simultaneous thermal and mechanical cycling

- Externally imposed constraint on deformation

- Temperature and deformation controlled

- Additional complexity: thermal strain \pm mechanical strain 


\section{Uniaxial Thermomechanical Fatigue (TMF)}

- Phasing between mechanical strain and temperature

- Typically $\theta=0^{\circ}$ (in-phase) or $\theta=180^{\circ}$ (out-of-phase) [Carden and Slade, 1969]

- Clockwise and counter clockwise diamonds depending upon application

- Standards for uniaxial TMF testing

- ASTM E 2368 (2010)

- ISO FDIS-12111 (2012)

- TMF life estimation approaches

- Phenomenological models and physical mechanism(s) based models

- Creep, fatigue, creep-fatigue interaction and oxidation based models

- TMF deformation prediction methods

- Plasticity and creep deformation models (non-unified)

- Unified constitutive models

Reference: Sehitoglu, H., "Thermal and Thermomechanical Fatigue of Structural Alloys," Fatigue and Fracture, ASM Handbook, Volume 19, 1996, pp. 527-556. 
MECHANICAL STRESS-STRAIN HYSTERESIS LOOP FOR

THERMAL-MECHANICAL STRAIN CYCLE

ILLUSTRATING CREEP STRESS LEVELS USED FOR PARTITIONING STRAINS

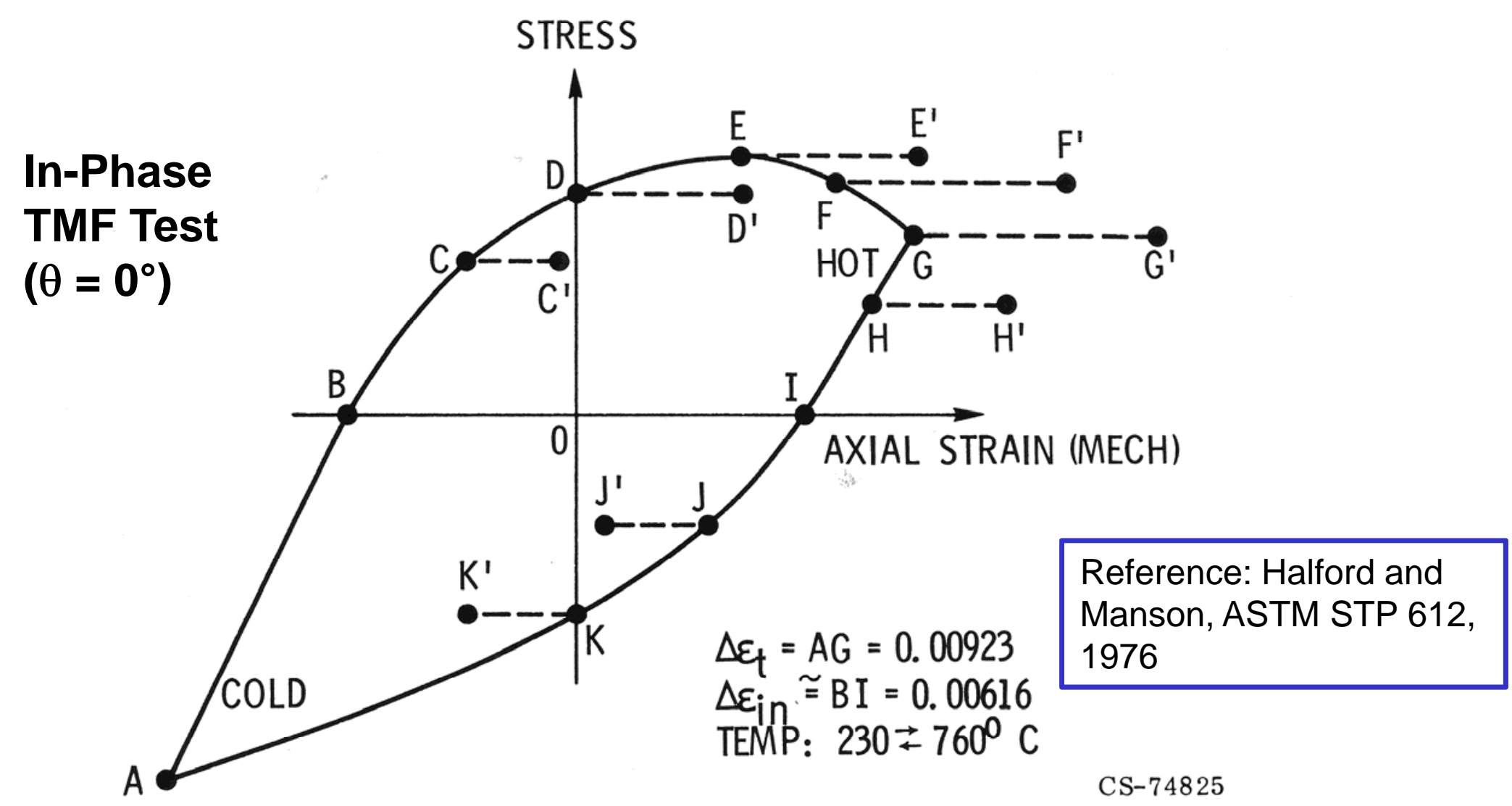

Experimental technique for determining creep strains within an in-phase thermomechanical hysteresis loop 
Uniaxial Bithermal and TMF Life Relations for Haynes 188 from Experiments $\left(316\right.$ to $760{ }^{\circ} \mathrm{C}$ )

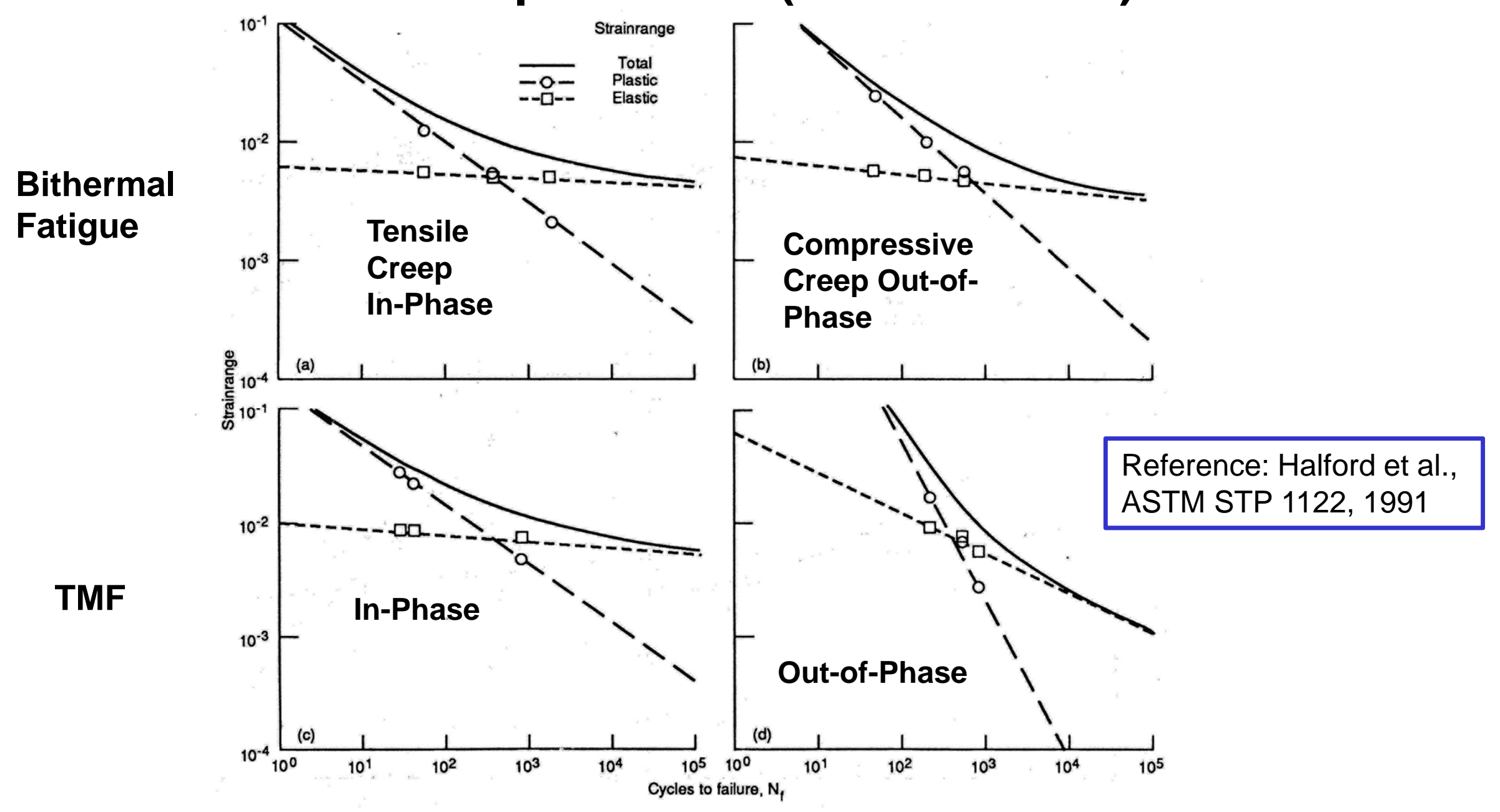

Bithermal fatigue data and deformation behavior used as input to predict thermomechanical fatigue lives 


\section{TMF Life Estimations from Bithermal Fatigue Data Using Total Strainrange SRP}

TS-SRP Approach

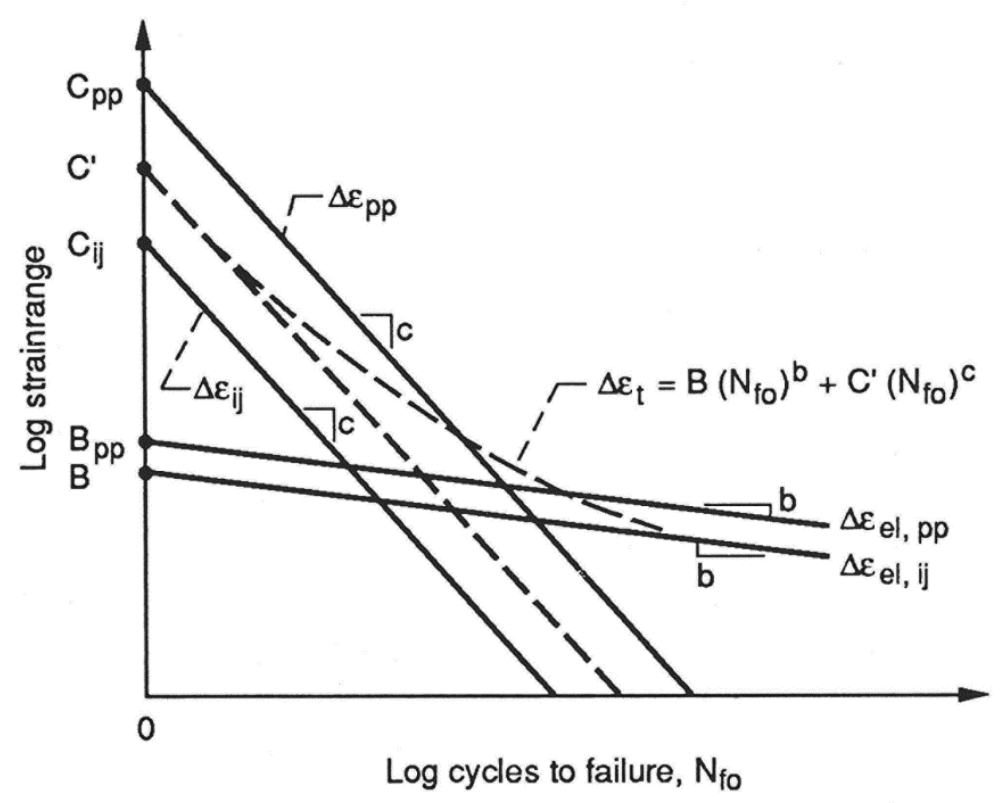

Estimations

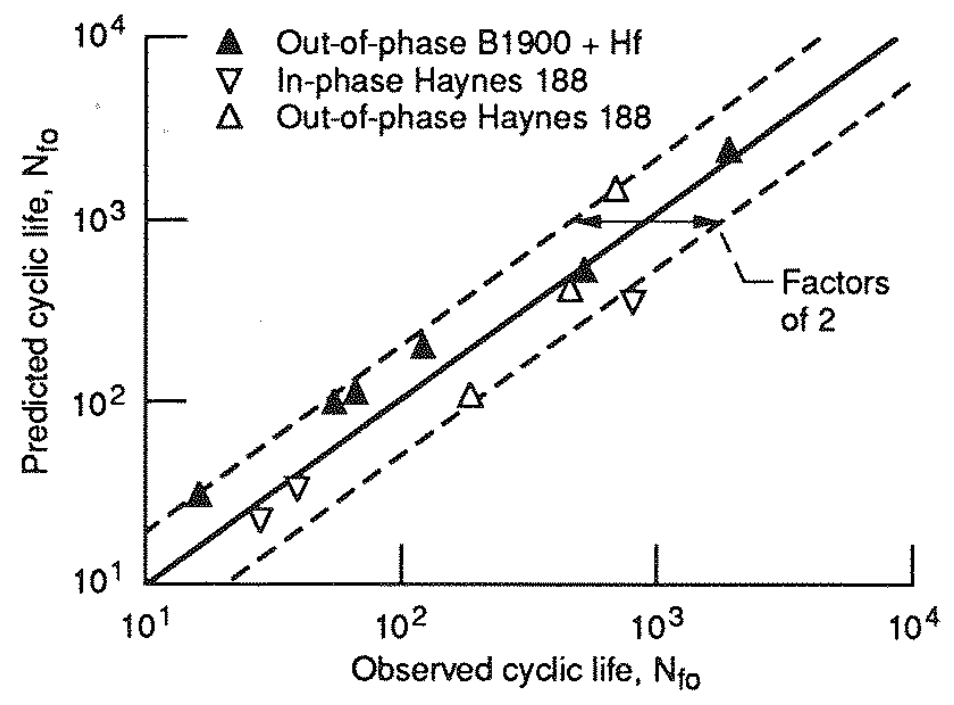

Reference: Halford et al., ASTM STP 1122, 1991

Total strain range life curve is established for each specific type of TMF cycle using bithermal fatigue data and simplified flow equations 


\section{Multiaxial and Thermomechanical Fatigue}

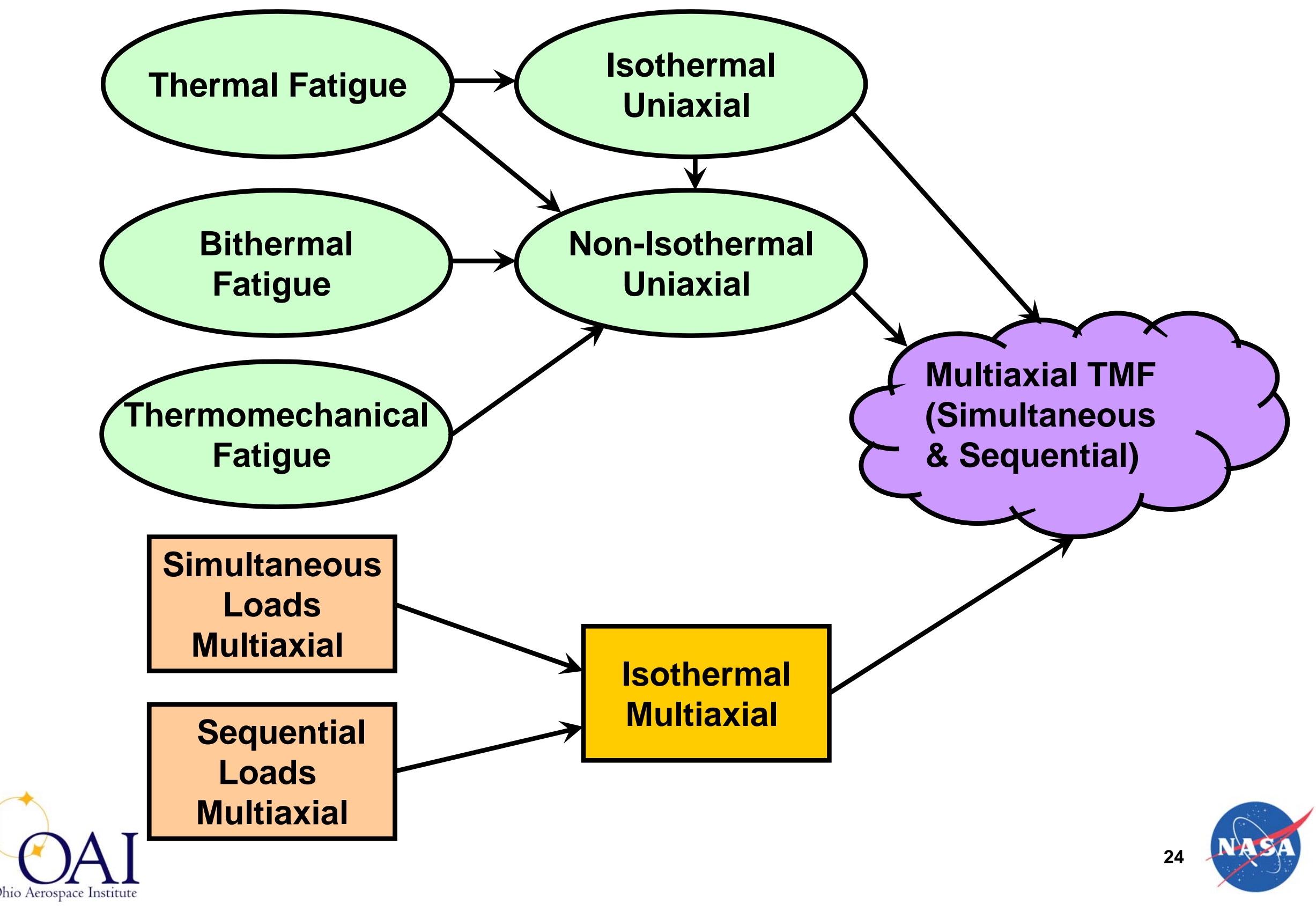




\section{Isothermal Multiaxial Fatigue}

- Multiaxial Loading

- Proportional and non-proportional loading (in-phase and out-of-phase loading)

- Simultaneous versus sequential loading

- Muliaxial Fatigue Life Correlation Methods

- Triaxiality factor based approaches (Davis and Connelly, 1959)

- Critical plane based approaches (Brown and Miller, 1973)

- Cyclic hysteretic energy or equivalent parameters (Halford and Morrow, 1962)

References:

[1] Garud., " Multiaxial Fatigue: A Survey of the State of the Art," Journal of Testing and Evaluation, JTEVA, Vol. 9, No. 3, 1981, pp. 165-178.

[2] B.-R. You and S.-B. Lee, A Critical Review on Multiaxial Fatigue Assessment of Metals, International Journal of Fatigue, Vol. 18, Issue 4, May 1996, pp. 235-244.

[3] McDowell, D. L., "Multiaxial Fatigue Strength," Fatigue and Fracture, ASM Handbook, Volume 19, 1996, pp. 263-273. 


\section{Isothermal Fatigue - Types of Multiaxial Loads}

- Axial, torsional, and combined axial-torsional loads

- Relatively simple form of multiaxial loading

- Thin-walled tubular specimens (trade off between torsional buckling and thin-wall to generate nearly uniform shear stress)

- ASTM Standard E 2207 (2008)

- ISO/FDIS 1352 (2011)

- Combined torsional and bending loads

- Torque shafts in automotive applications

- Relatively lower temperatures and typically high-cycle fatigue

- Combined biaxial loads

- Thin-walled tubular specimens with internal and/or external pressure (pressure vessels)

- Cruciform specimens tested in-plane with four independent actuators typically with centroid control

- Combined triaxial loads

- 3-D version of a cruciform specimen (complicated design and most expensive to fabricate)

- Primary goal is to evaluate the influence of hydrostatic stress on fatigue life 


\section{Examples of Multiaxial Test Specimens}

Thin-walled Tubular Specimen and Axial-Torsional Test Rig
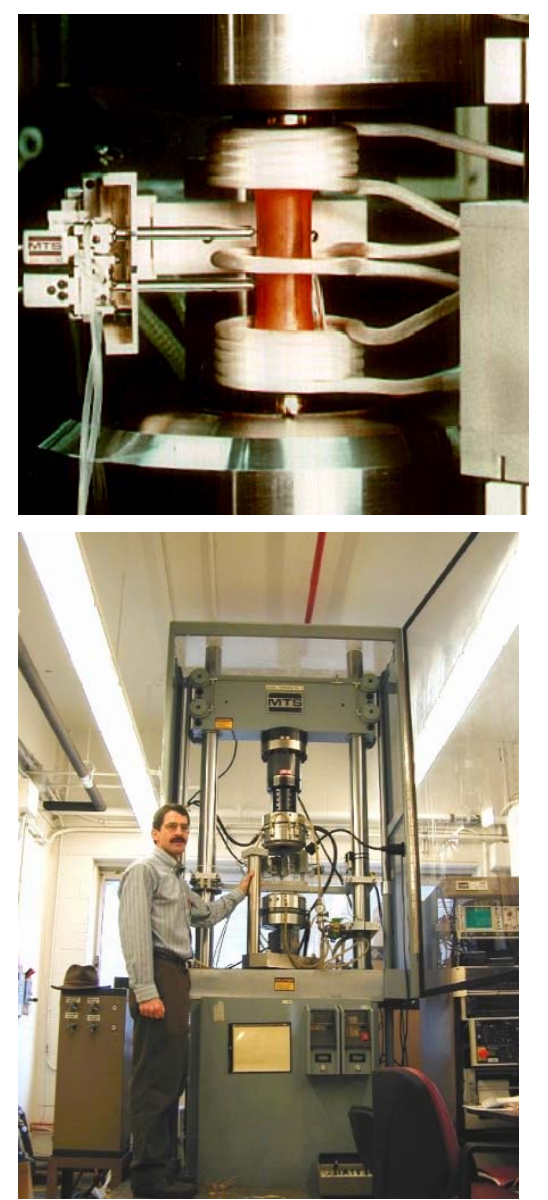

\section{Cruciform Specimen and} In-plane Biaxial Test Rig
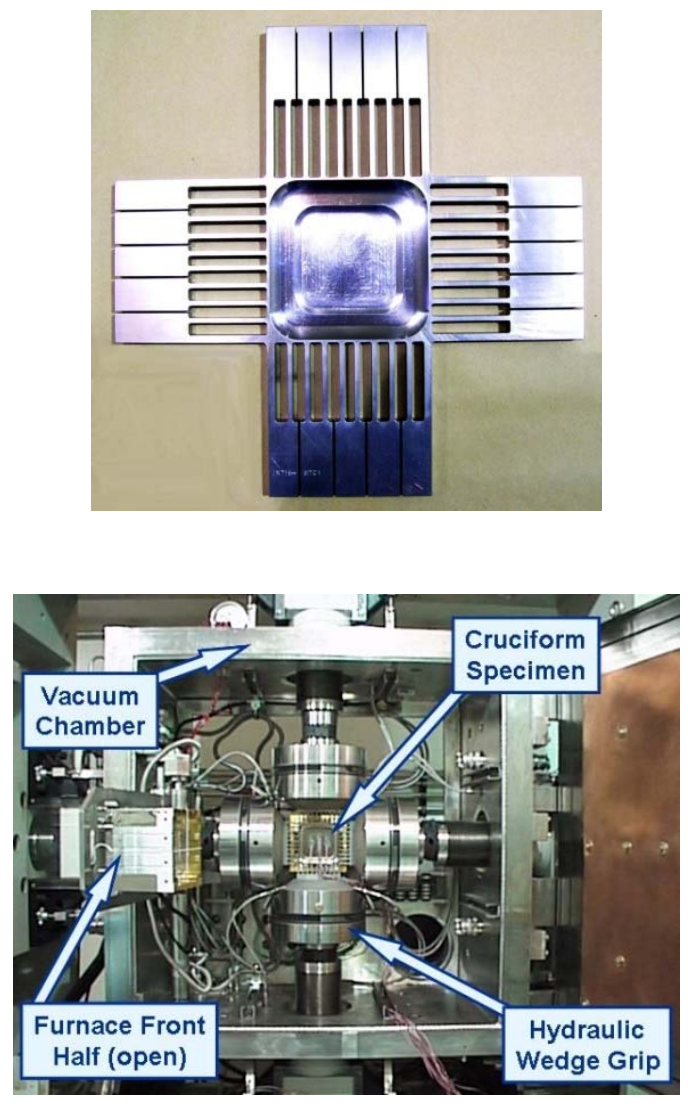

Triaxial Cruciform Specimen for Creep Rupture in Triaxial Tension

Source: Hayhurst and Felce (1985), Techniques for Multiaxial Creep Testing, D. J. Gooch and I. M. How (Eds.), Elsevier, 1986, p. 241
References: Bartolotta, Ellis, and Abdul-Aziz, ASTM STP 1280, 1997 \& Krause and Bartolotta, ASTM STP 1387, 2000 


\section{Multiaxial and Thermomechanical Fatigue}

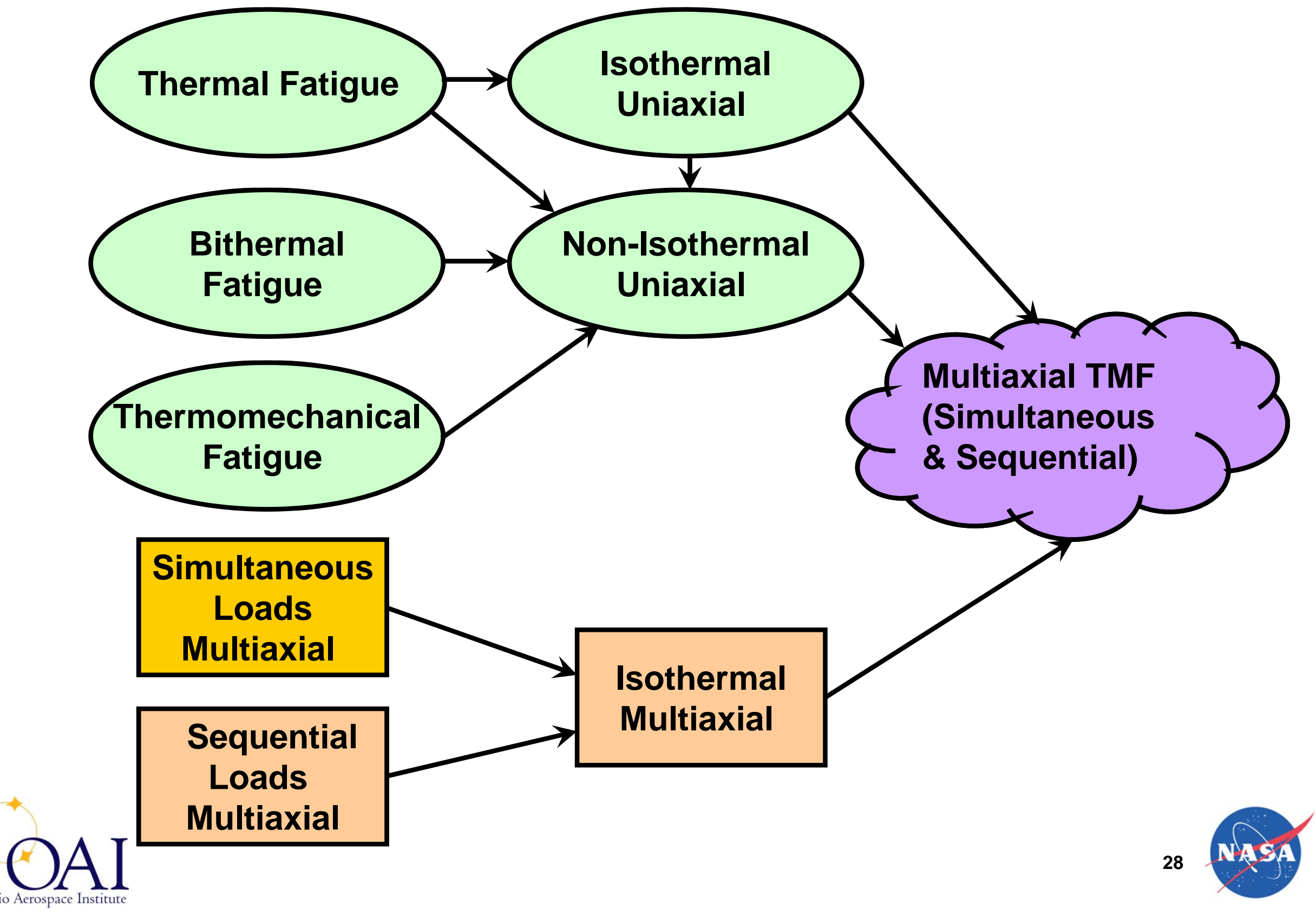




\section{Isothermal, Axial-Torsional, In- and Out-of-Phase Fatigue (Simultaneous Loading), $\lambda=\gamma_{\mathrm{a}} / \varepsilon_{\mathrm{a}}$}

In-Phase

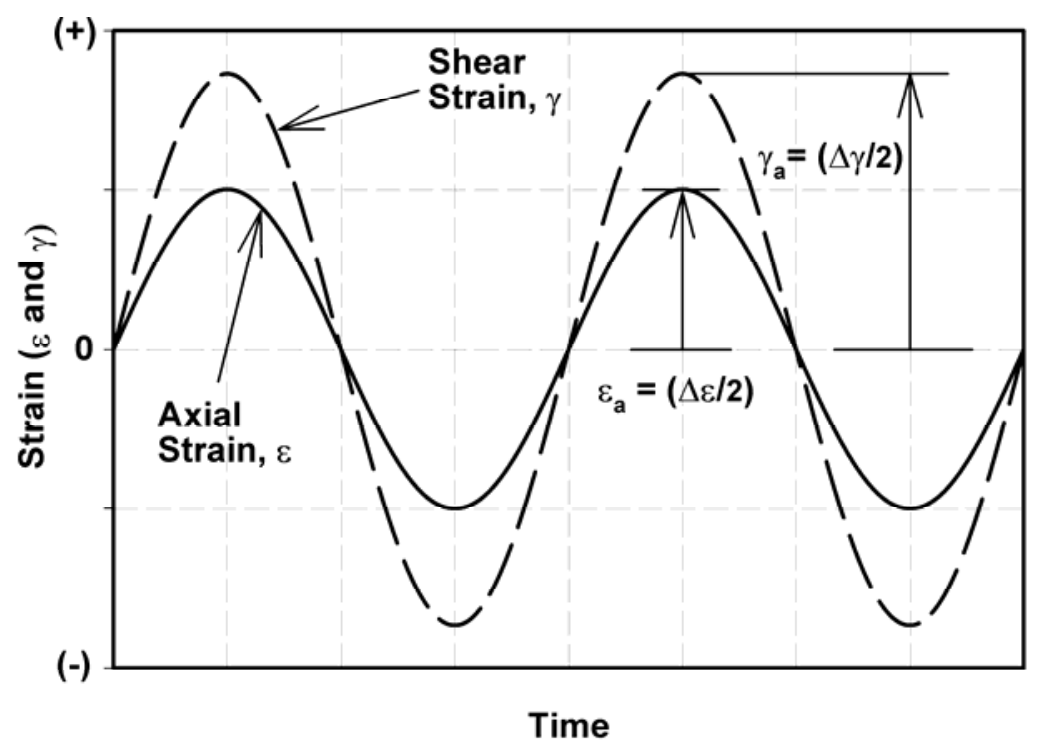

Phase angle, $\phi=0^{\circ}$
Out-of-Phase

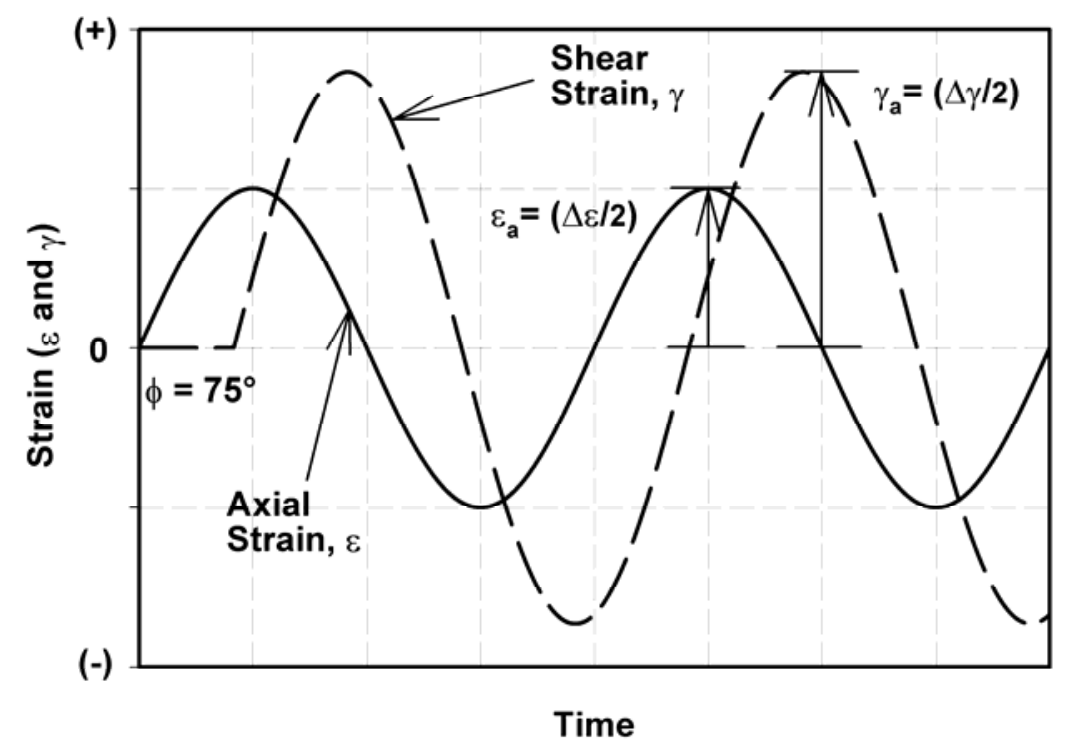

Phase angle, $\phi=75^{\circ}$

For out-of-phase tests, mechanical phase angle, $\phi=90^{\circ}$ is typical 


\section{Isothermal Multiaxial Fatigue: Life Estimation}

- Multiaxial Fatigue Life Controlling Parameters

- Phasing of load components (in-phase vs. out-of-phase)

- Mode of failure (tensile vs. shear) exhibited by the material

- Temperature

- Four multiaxial fatigue life estimated methods illustrated

- Von Mises equivalent strain range model

- Modified multiaxiality factor approach

- Modified Smith-Watson-Topper Parameter

- Critical shear plane method of Fatemi, Socie, and Kurath

Applicability of any method is dependent on loading phase, mode of failure exhibited by the material, and temperature 


\section{VON MISES EQUIVALENT STRAIN RANGE MODEL}

$\Delta \varepsilon_{e q}=\frac{\left[\left(\Delta \varepsilon_{x x}-\Delta \varepsilon_{y y}\right)^{2}+\left(\Delta \varepsilon_{y y}-\Delta \varepsilon_{z z}\right)^{2}+\left(\Delta \varepsilon_{z z}-\Delta \varepsilon_{x x}\right)^{2}+\frac{3}{2}\left(\Delta \gamma_{x y}^{2}+\Delta \gamma_{y z}^{2}+\Delta \gamma_{z x}^{2}\right)\right]^{\frac{1}{2}}}{\sqrt{2}\left(1+v_{e f f}\right)}$

$$
\begin{aligned}
& v_{e f f}=\left[\frac{\Delta \varepsilon_{e} v_{e}+\Delta \varepsilon_{p} v_{p}}{\Delta \varepsilon}\right] \\
& \text { where: } \Delta \varepsilon_{e}=\Delta \sigma / E \\
& \text { and: } \Delta \varepsilon_{p}=\Delta \varepsilon-\Delta \varepsilon_{e}
\end{aligned}
$$


LIFE PREDICTION: VON MISES EQUIVALENT STRAIN RANGE MODEL

Haynes 188 at $316^{\circ} \mathrm{C}$

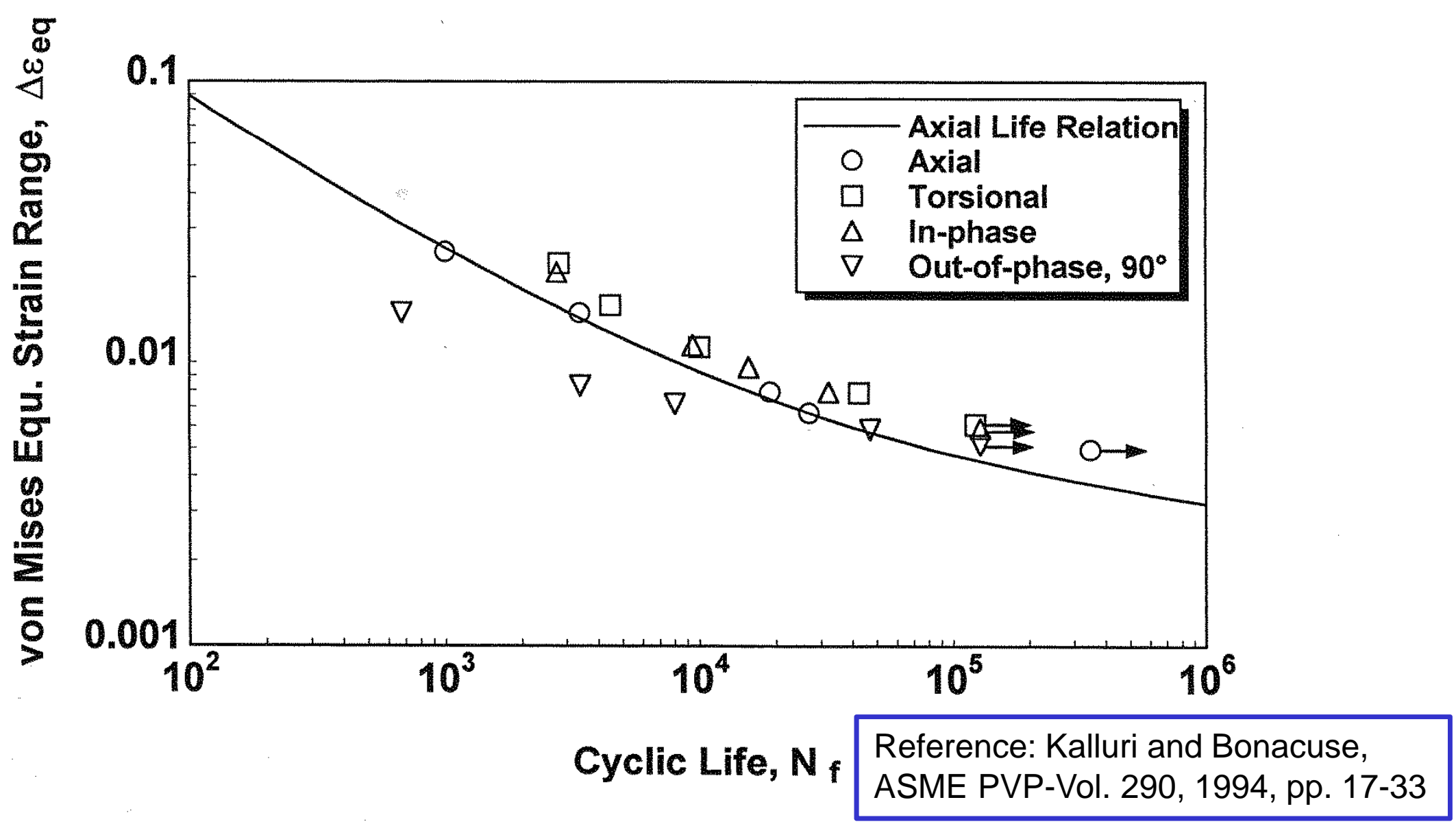

Predictions of mechanically out-of-phase tests are higher (unconservative) due to additional hardening 


\section{MODIFIED MULTIAXIALITY FACTOR APPROACH}

$$
M F \Delta \varepsilon_{e q}=M F^{(1-b / c)} B\left(N_{f}\right)^{b}+C\left(N_{f}\right)^{c}
$$

where,

$$
\begin{aligned}
& M F=\frac{1}{2-T F} \quad ; T F \leq 1 \\
& M F=T F ; T F \geq 1
\end{aligned}
$$

and: $\quad T F=\frac{\sigma_{1}+\sigma_{2}+\sigma_{3}}{\frac{1}{\sqrt{2}} \sqrt{\left(\sigma_{1}-\sigma_{2}\right)^{2}+\left(\sigma_{2}-\sigma_{3}\right)^{2}+\left(\sigma_{3}-\sigma_{1}\right)^{2}}}$

Uniaxial fatigue life relation and cyclic stress strain curve used with Von Mises equivalent strain range and MF 
LIFE PREDICTION: MODIFIED MULTIAXIALITY FACTOR APPROACH Haynes 188 at $316^{\circ} \mathrm{C}$

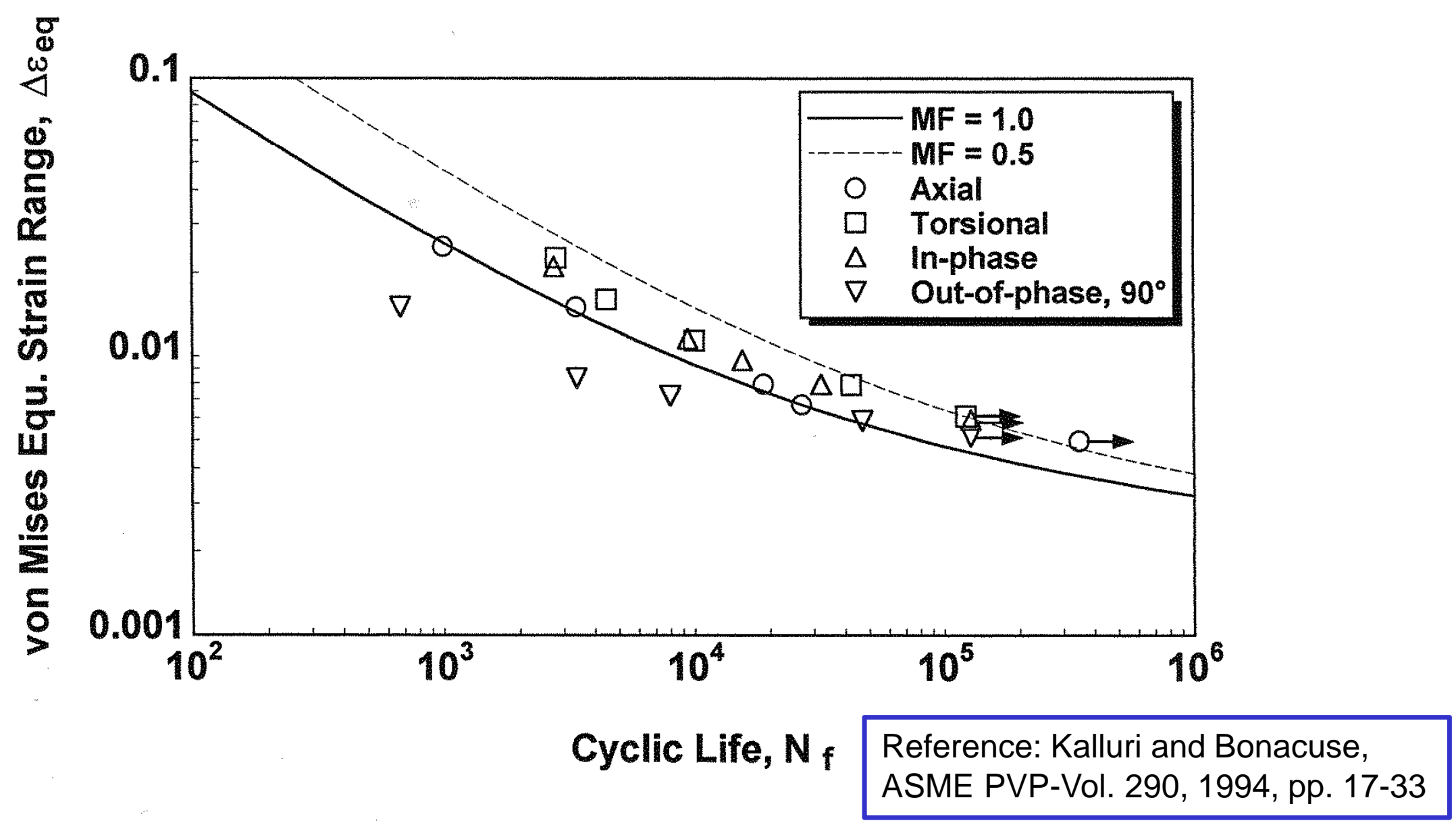

Predictions of mechanically out-of-phase tests are again higher (unconservative) due to additional hardening 


\section{MODIFIED SMITH-WATSON-TOPPER PARAMETER}

$$
\frac{\Delta \varepsilon_{1}}{2} \sigma_{1}^{\max }=\sigma_{f}^{\prime} \varepsilon_{f}^{\prime}\left(2 N_{f}\right)^{b+c}+\frac{\sigma_{f}^{\prime 2}}{E}\left(2 N_{f}\right)^{2 b}
$$

Where,

$\varepsilon_{1} \quad$ First principal strain amplitude

Reference: Socie, Trans. of ASME, J. of Eng. Mat. and Tech., vol. 109, no. 4, 1987, pp. 293-298.

$\sigma_{1}^{\max } \quad$ Maximum stress on the maximum principal strain plane

$\sigma_{f}^{\prime} \quad$ Axial fatigue strength coefficient

$\varepsilon_{f}^{\prime} \quad$ Axial fatigue ductility coefficient

b, c Exponents of axial elastic and plastic strain-life relations

Modification of the original SWT parameter (1970) for multiaxial fatigue - materials with tensile mode of failure 
LIFE PREDICTION: MODIFIED SMITH-WATSON-TOPPER PARAMETER

Haynes 188 at $316^{\circ} \mathrm{C}$

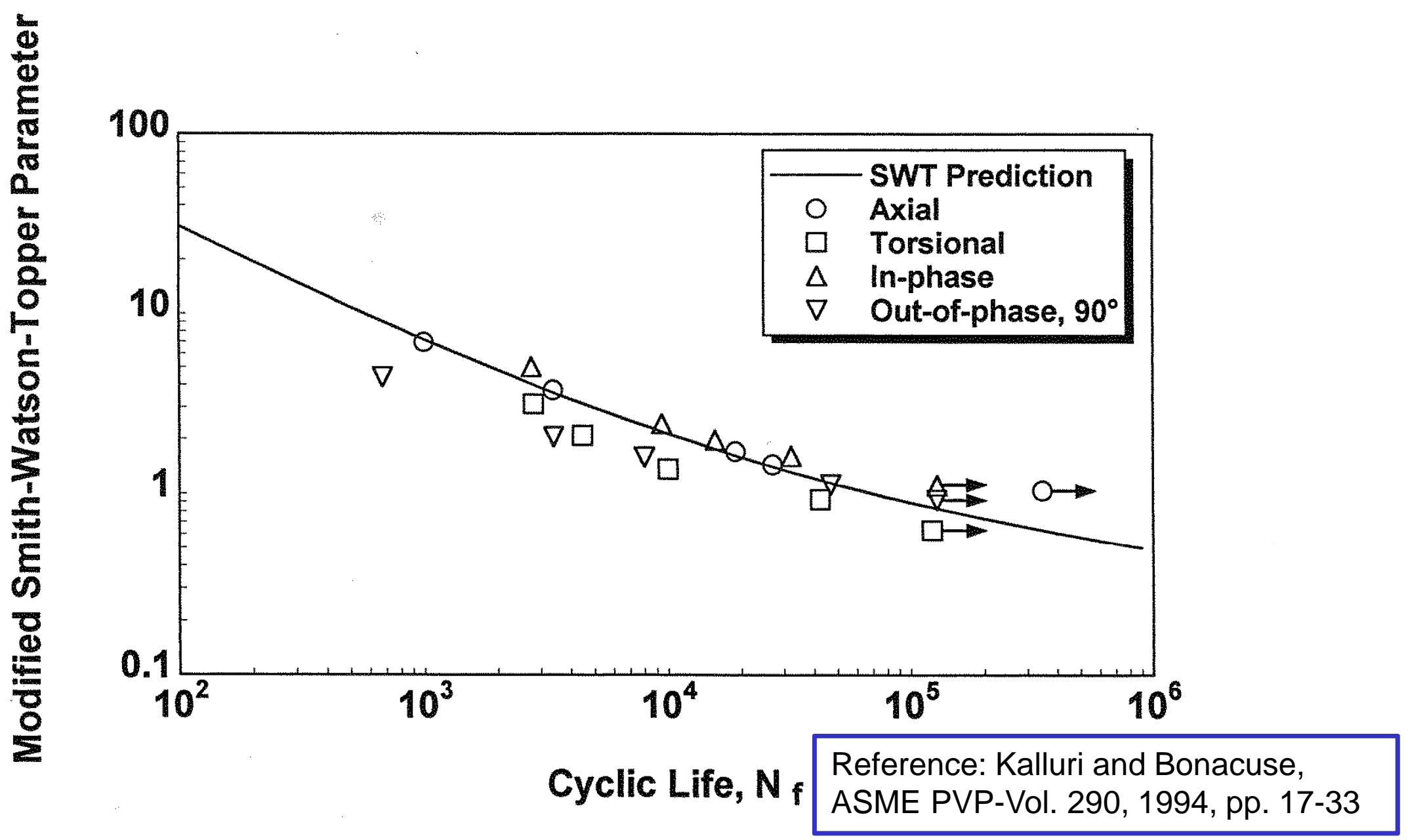

Predictions of some torsional and mechanically out-ofphase tests are slightly higher (slightly unconservative) 
CRITICAL SHEAR PLANE METHOD OF FATEMI, SOCIE, AND KURATH

$$
\begin{aligned}
\gamma_{\max }\left(1+k \frac{\sigma_{n}^{\max }}{\sigma_{y}}\right)=\left(1+v_{e}\right) \frac{\sigma_{f}^{\prime}}{E}\left(2 N_{f}\right)^{b}+\frac{k}{2}\left(1+v_{e}\right) \frac{\sigma_{f}^{\prime 2}}{E \sigma_{y}}\left(2 N_{f}\right)^{2 b} \\
+\left(1+v_{p}\right) \varepsilon_{f}^{\prime}\left(2 N_{f}\right)^{c}+\frac{k}{2}\left(1+v_{p}\right) \varepsilon_{f}^{\prime} \frac{\sigma_{f}^{\prime}}{\sigma_{y}}\left(2 N_{f}\right)^{b+c}
\end{aligned}
$$

Where,

$\gamma_{\max } \quad$ Maximum engineering shear strain amplitude

$\sigma_{n}^{\max } \quad$ Maximum normal stress on the maximum shear strain plane

$k$ Constant determined from axial and torsional fatigue data

$\sigma_{y} \quad$ Axial yield strength

$\sigma_{f}^{\prime} \quad$ Axial fatigue strength coefficient

$\varepsilon_{f}^{\prime} \quad$ Axial fatigue ductility coefficient

b, c Exponents of axial elastic and plastic strain-life relations

Max. shear strain on critical shear plane and max. normal stress on that plane - materials with shear mode of failure 
LIFE PREDICTION: CRITICAL SHEAR PLANE METHOD OF FATEMI,

SOCIE, AND KURATH

Haynes 188 at $316^{\circ} \mathrm{C}$

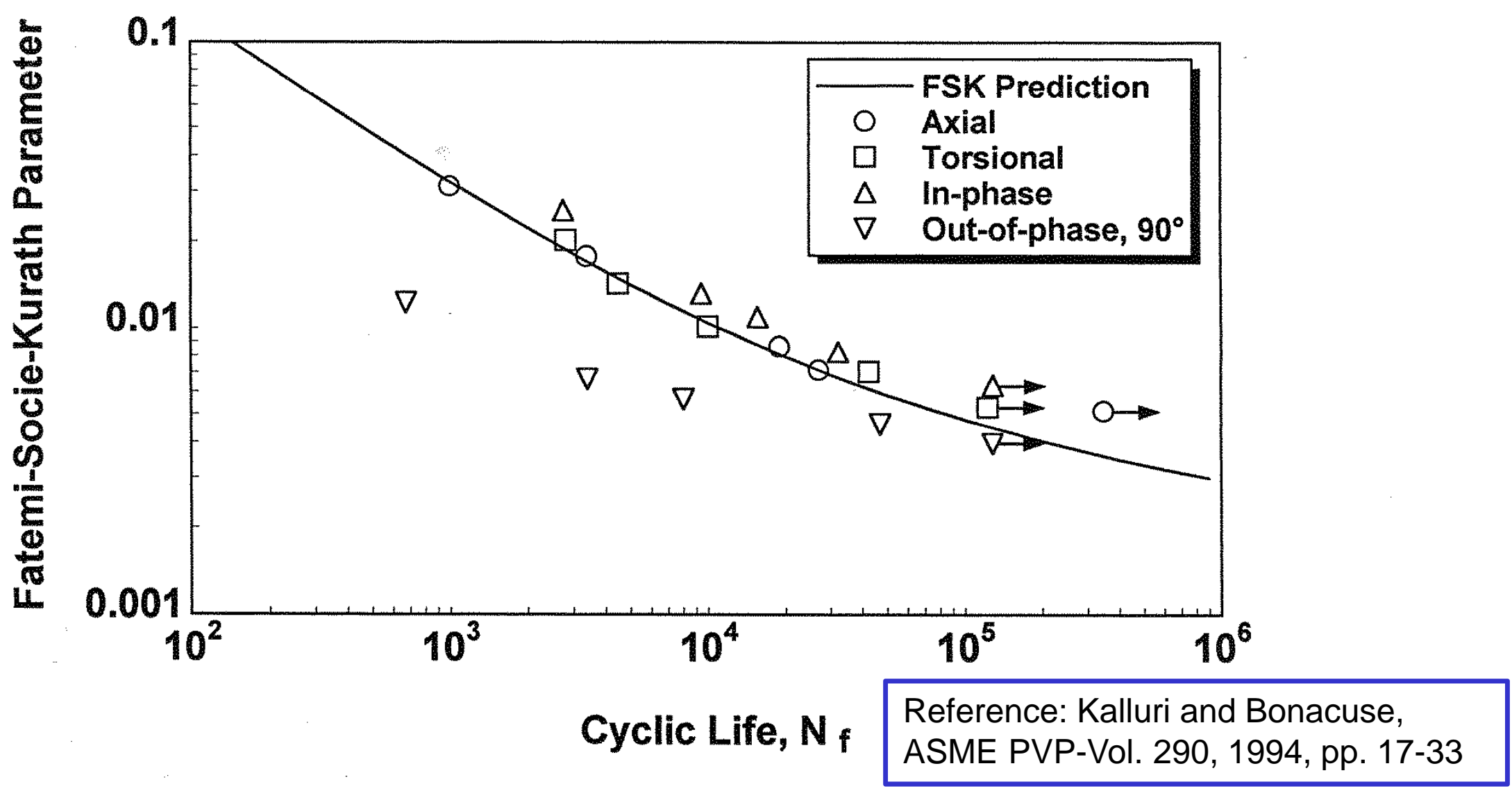

Predictions of mechanically out-of-phase tests are much higher (very unconservative) 


\section{Cyclic Hardening in Isothermal, Axial-Torsional, In- and Out-of-Phase Fatigue $(\lambda=\Delta \gamma / \Delta \varepsilon)$}
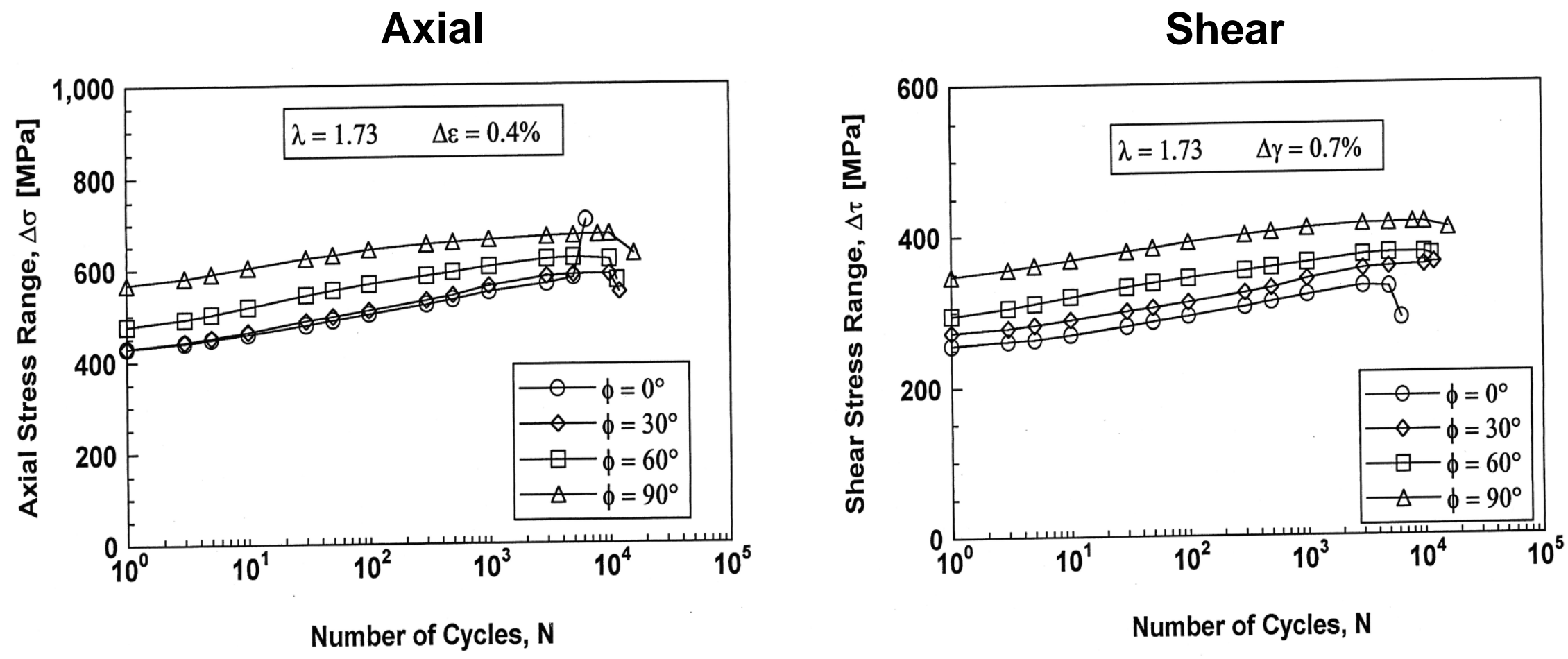

Reference: Bonacuse and Kalluri, ASTM STP 1184, 1994

In out-of-phase tests, cyclic hardening increases with mechanical phase angle, $\phi$ between axial $(\varepsilon)$ and shear $(\gamma)$ strains 


\section{Multiaxial and Thermomechanical Fatigue}

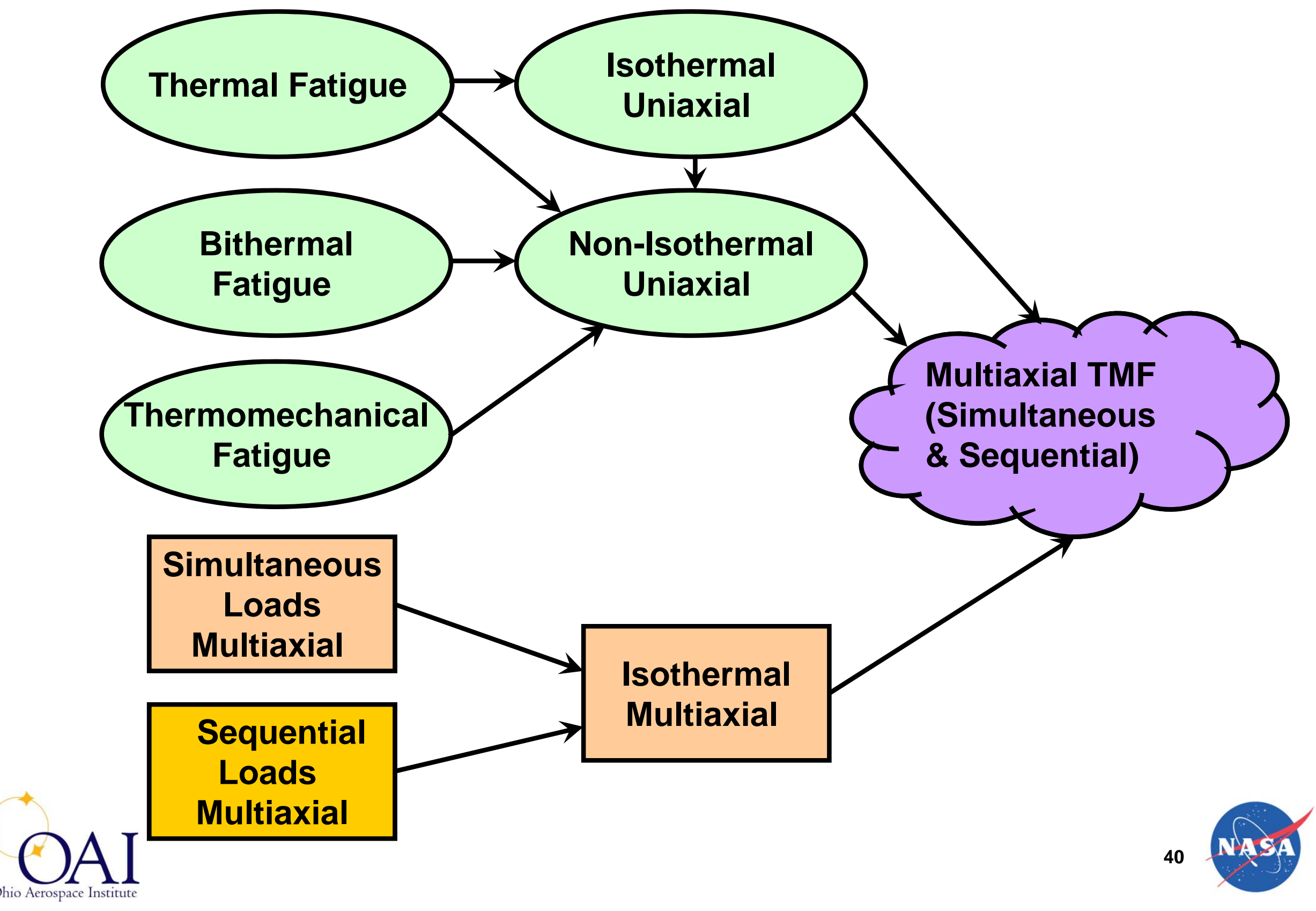




\section{Isothermal Axial and Torsional Cumulative Fatigue (Sequential Loading)}

- Historically, most investigations on cumulative fatigue limited to the same load-types (axial/axial, torsion/torsion, or rotating bending/rotating bending)

- Typical studies involve load order effects within a load-type (high/low or low/high)

- Dissimilar load-types can increase potential for interaction of damage (or mode of cracking)

- Evaluation of both load order and load-type sequencing effects is necessary

References:

[1] Miller, K. J., "Metal Fatigue-Past, Current, and Future," Proc. Inst. Mech. Eng., Vol. 205, 1991, pp. $1-14$.

[2] Weiss, J. and Pineau, A., "Continuous and Sequential Multiaxial Low-Cycle Fatigue Damage in 316 Stainless Steel," in Advances in Multiaxial Fatigue, ASTM STP 1191, D. L. McDowell and R. Ellis, Eds.,American Society for Testing and Materials, West Conshohocken, PA, 1993, pp. 183-203.

[3] Harada, S. and Endo, T., "On the Validity of Miner's Rule under Sequential Loading of Rotating Bending and Cyclic Torsion," in Fatigue Under Biaxial and Multiaxial Loading, ESIS10, K. Kussmaul, D. McDiarmid, and D. Socie, Eds., Mechanical Engineering Publications, London, 1991, pp. 161-178. 


\section{Schematics of LCF/HCF and HCF/LCF Cumulative Fatigue Tests on Haynes 188 at $538^{\circ} \mathrm{C}$}

\section{LCF/HCF}

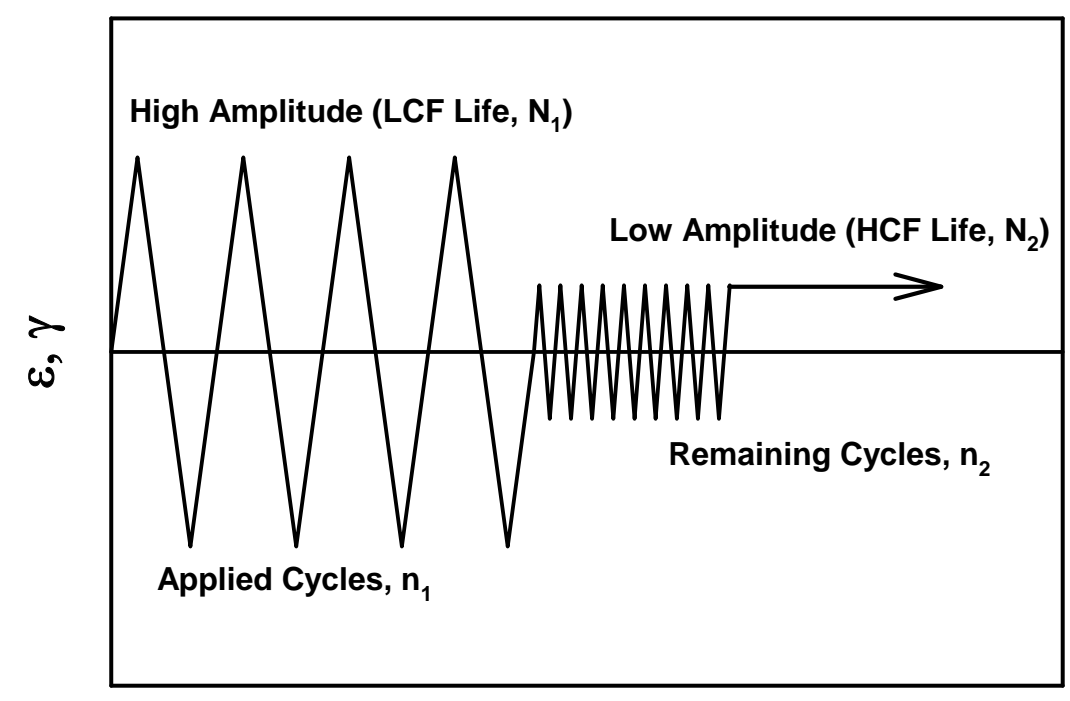

Time
HCF/LCF

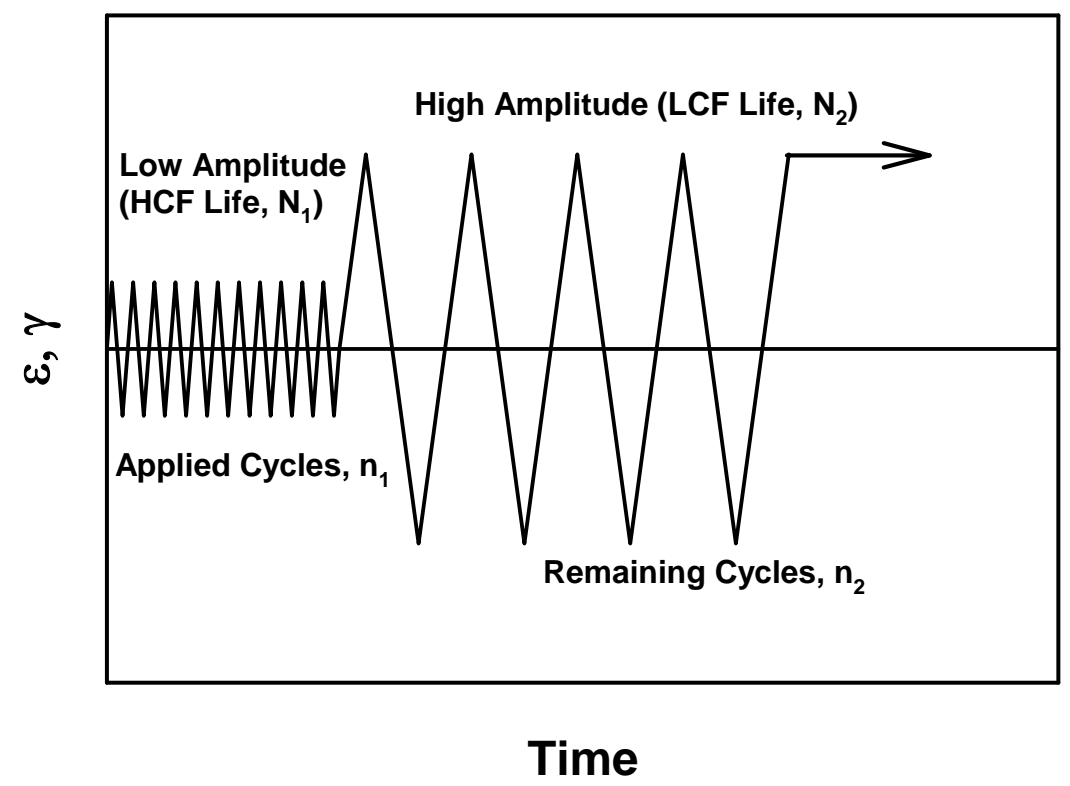

Applied Life Fraction: $n_{1} / N_{1}$; Remaining Life Fraction: $n_{2} / N_{2}$ 


\section{Cumulative Fatigue Life Prediction}

- Linear Damage Rule [Palmgren, Langer, and Miner] (LDR):

$$
\left(\frac{\mathrm{n}_{2}}{\mathrm{~N}_{2}}\right)=1-\left(\frac{\mathrm{n}_{1}}{\mathrm{~N}_{1}}\right)
$$

- Nonlinear Damage Curve Approach [Manson and Halford] (DCA):

$$
\left(\frac{\mathrm{n}_{2}}{\mathrm{~N}_{2}}\right)=1-\left(\frac{\mathrm{n}_{1}}{\mathrm{~N}_{1}}\right)^{\left(\frac{\mathrm{N}_{1}}{\mathrm{~N}_{2}}\right)^{0.4}}
$$

$\mathrm{n}_{1}$ and $\mathrm{n}_{2}$ are Applied Number of Cycles at Load Levels 1 \& 2 and $\mathrm{N}_{1}$ and $\mathrm{N}_{2}$ are Fatigue Lives at Load Levels 1 \& 2, respectively. 


\section{Axial $\left(\Delta \varepsilon_{\text {High }}=2.0 \%\right) /$ Axial $\left(\Delta \varepsilon_{\text {Low }}=0.67 \%\right)$ Interaction Haynes 188 at $538^{\circ} \mathrm{C}$}

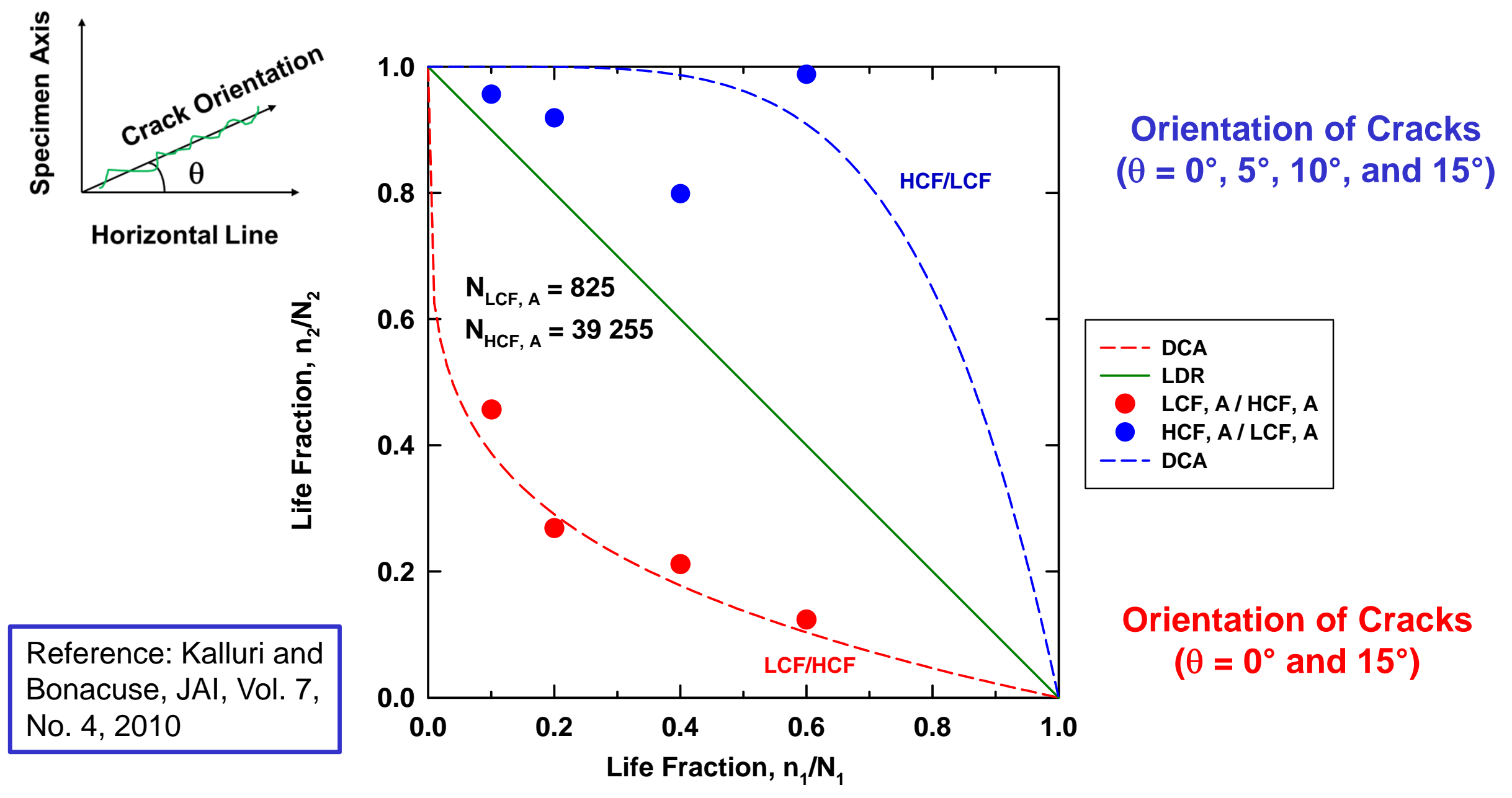

For all LCF/HCF data and HCF/LCF data for which $n_{1} / N_{1}>0.4$, DCA is Better than LDR 


\section{Axial $\left(\Delta \varepsilon_{\text {High }}=2.0 \%\right) /$ Torsional $\left(\Delta \gamma_{\text {Low }}=1.2 \%\right)$ Interaction Haynes 188 at $538^{\circ} \mathrm{C}$}

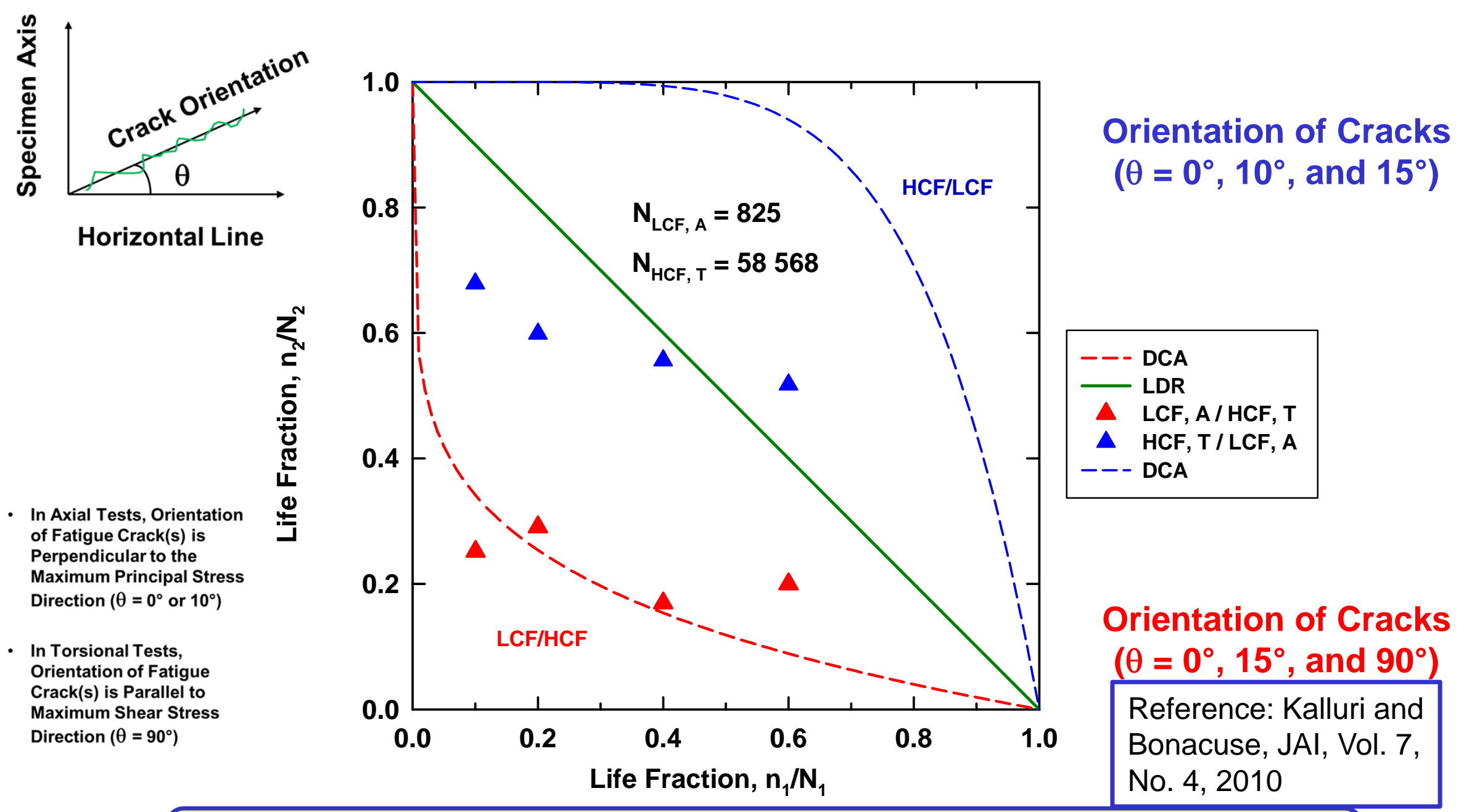

For all LCF/HCF data DCA is Better than LDR; However, for HCFILCF data LDR is Better than DCA 


\section{Torsional $\left(\Delta \gamma_{\text {High }}=3.5 \%\right)$ I Axial $\left(\Delta \varepsilon_{\text {Low }}=0.67 \%\right)$ Interaction Haynes 188 at $538^{\circ} \mathrm{C}$}
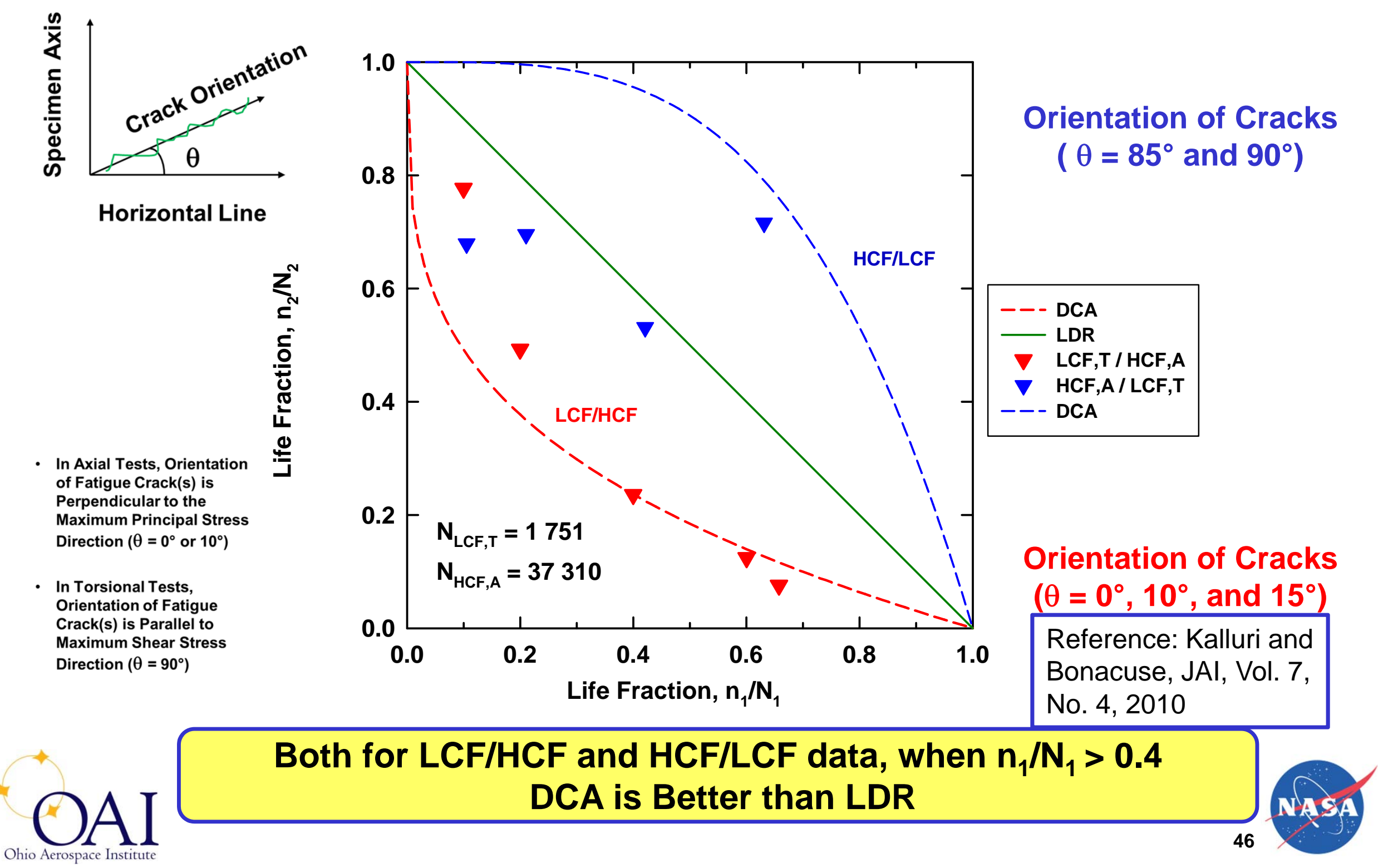


\section{Multiaxial and Thermomechanical Fatigue}

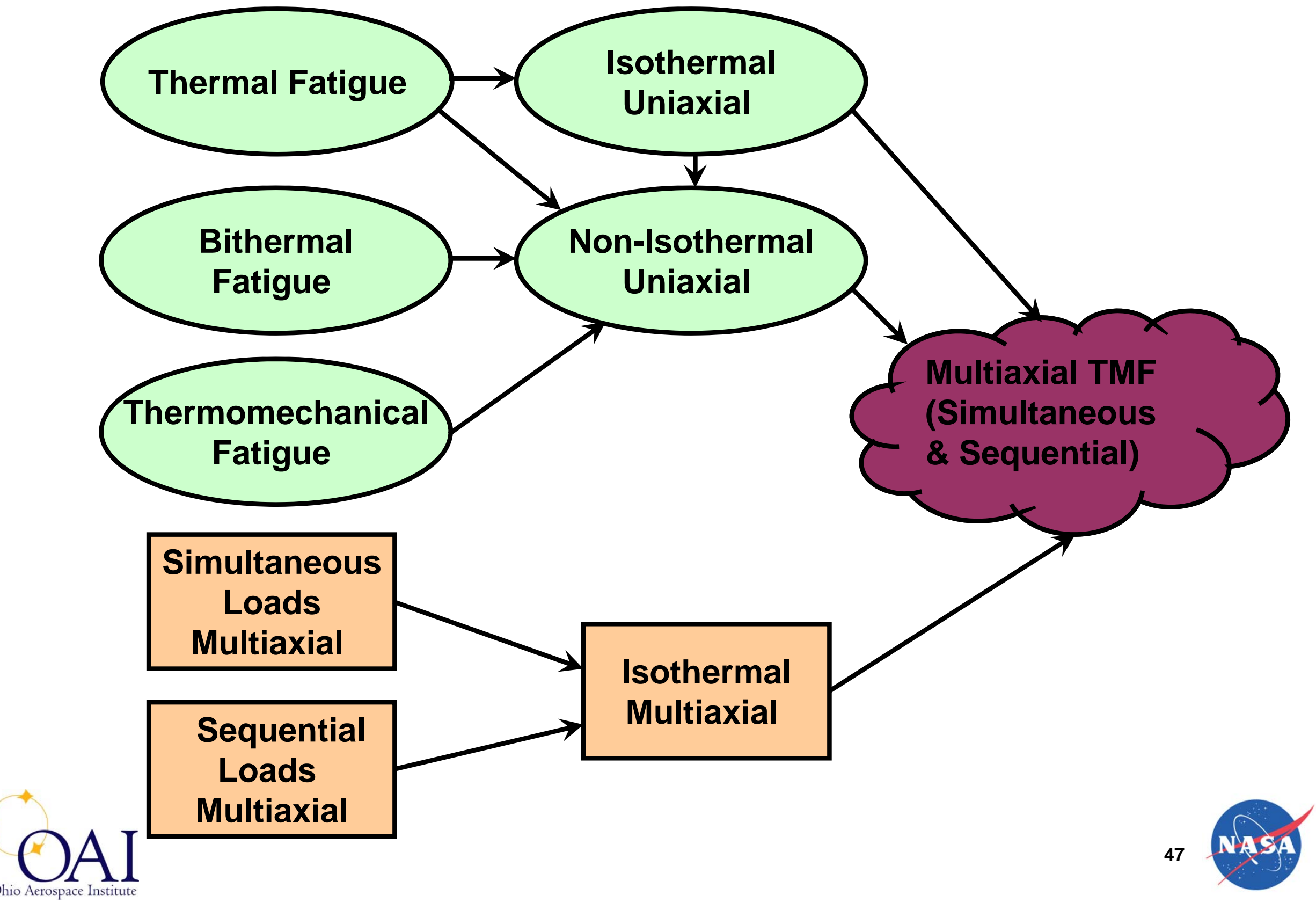




\section{Multiaxial, Thermomechanical Fatigue}

- Torsional, TMF testing

- Jordan, 1987 (4 $4^{\text {th }}$ Annual SEM Hostile Environments and High Temperature Measurements Conference; Turbine blade superalloy (PWA 1480) tested between 425 to $828^{\circ} \mathrm{C}$ )

- Bakis, Castelli, and Ellis, 1993 (ASTM STP 1191; Hastelloy-X tested between 400 to $600{ }^{\circ} \mathrm{C}, 600$ to $800^{\circ} \mathrm{C}, 800$ to $1000{ }^{\circ} \mathrm{C}$ )

- Axial-Torsional TMF testing

- Bonacuse and Kalluri, [1995 - AGARD Conference]; Kalluri and Bonacuse, [1997, ASTM STP 1280] (Haynes 188 alloy tested between 316 and $760^{\circ} \mathrm{C}$ )

- Meersmann, Ziebs et al. [1995 - AGARD Conference and 1996 - Kluwer Academic Publishers] (Inconel 738 LC and Single Crystal alloy SC16)

- Zamrik et al. [1996 - Kluwer Academic Publishers and 2000 - ASTM STP 1387] (Austenitic stainless steel tested between 399 and $621^{\circ} \mathrm{C}$ )

- Brookes et al., 2010 (Materials Science and Engineering A; Near $\gamma$-TiAl alloy TNB-15 tested between 400 to $800^{\circ} \mathrm{C}$ ) 


\section{Mechanically In-Phase \& Thermally In-Phase (MIPTIP)}
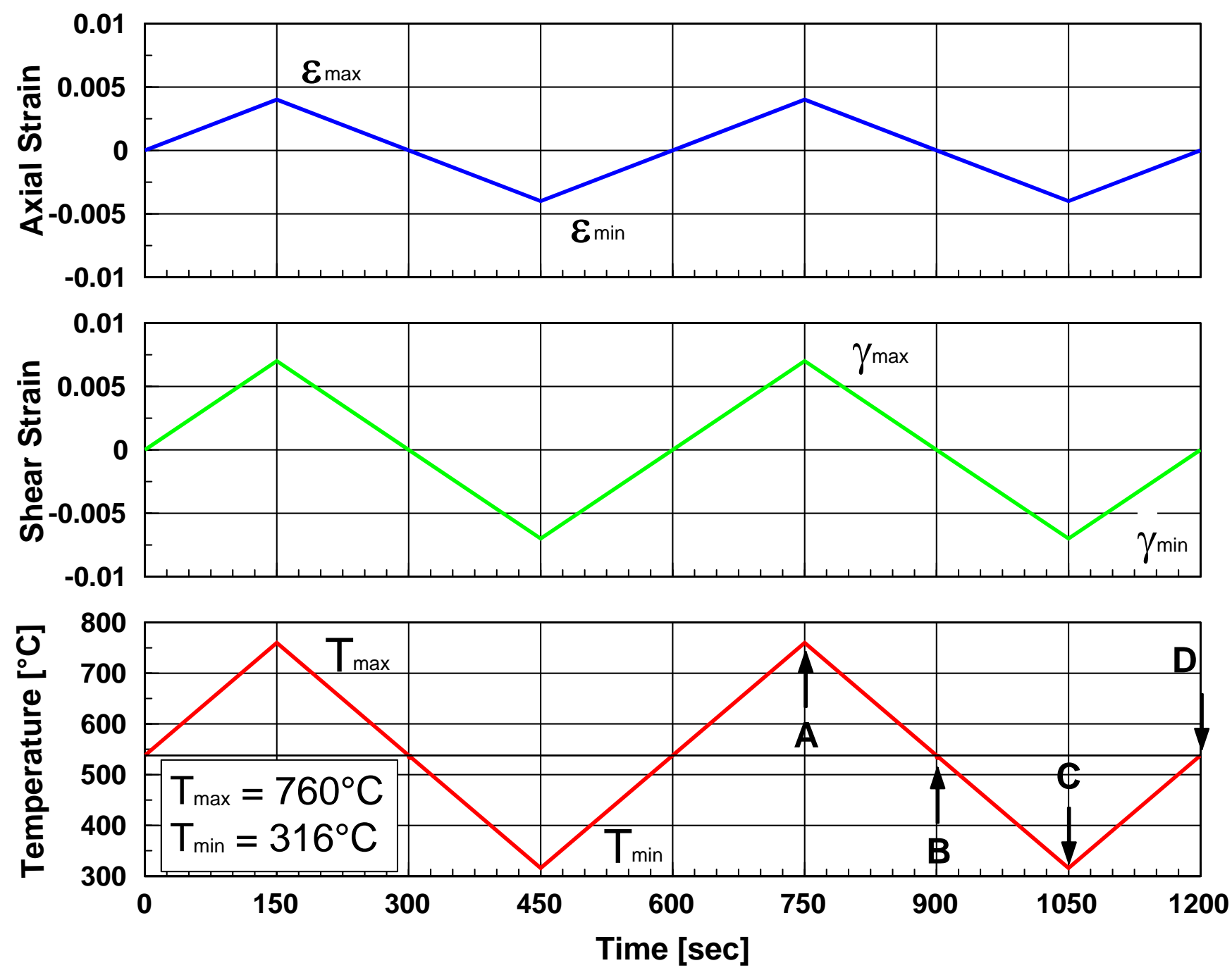


\section{Mechanically In-Phase \& Thermally Out-of-Phase (MIPTOP)}
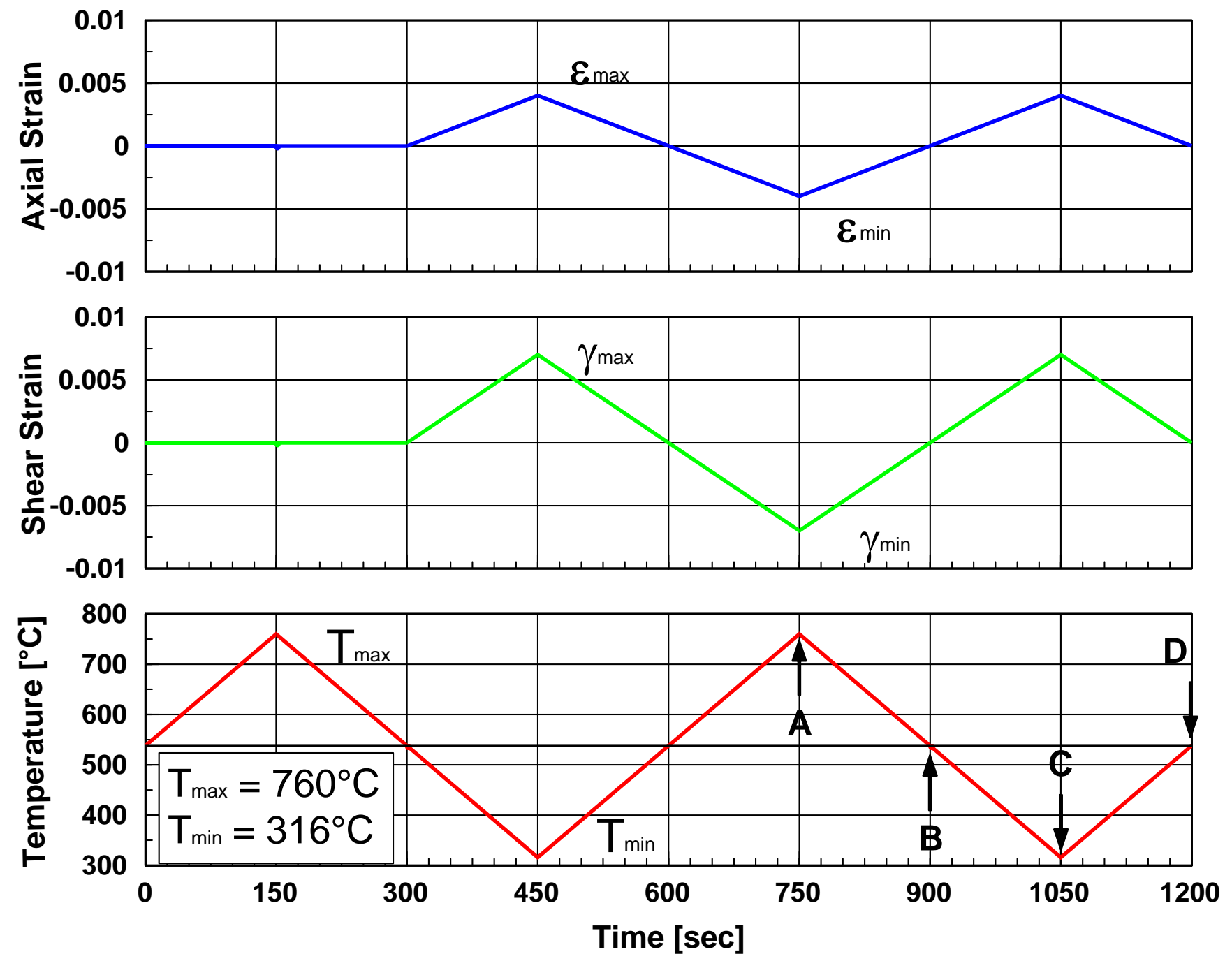


\section{Mechanically Out-of-Phase \& Thermally In-Phase (MOPTIP)}
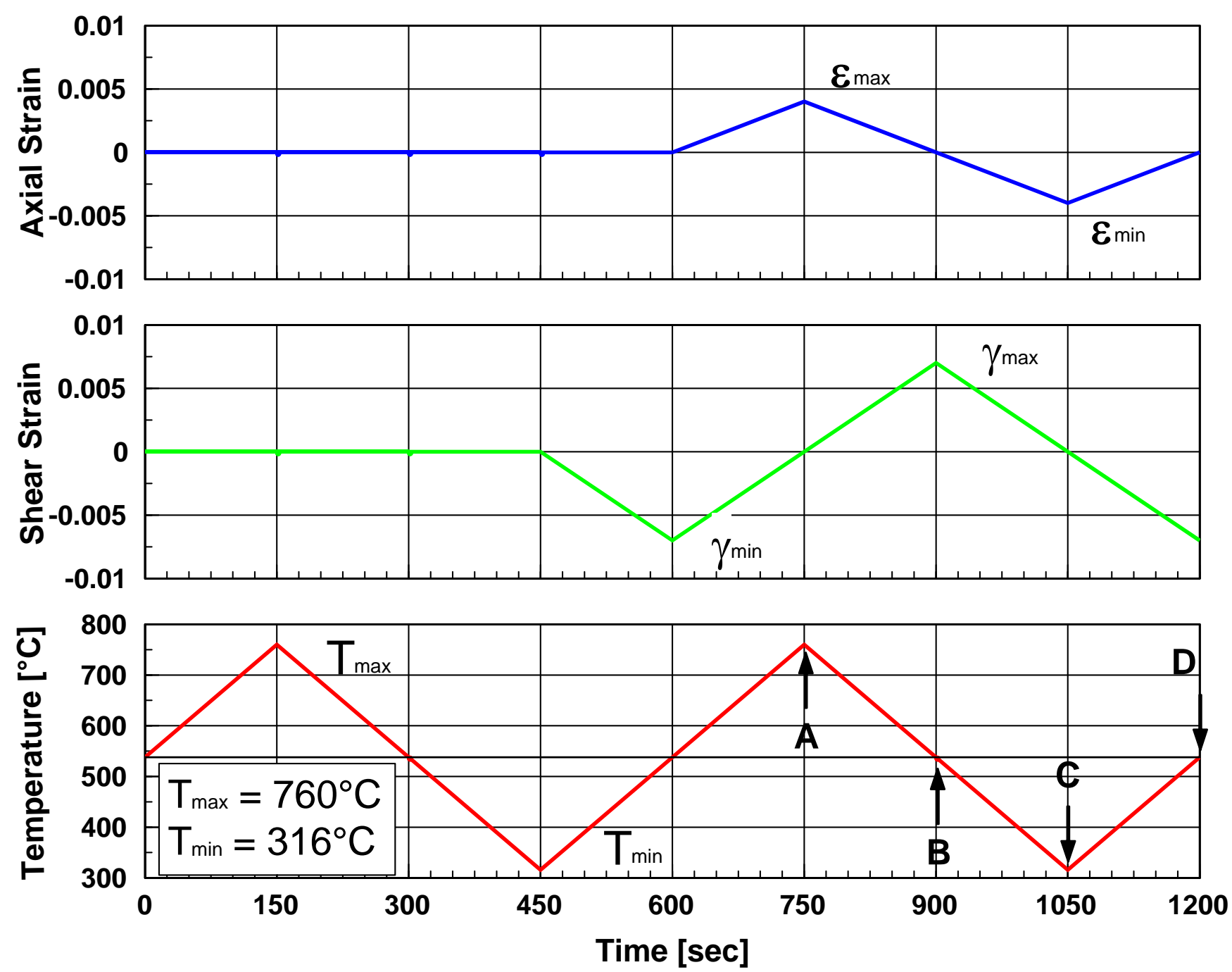


\section{Mechanically Out-of-Phase \& Thermally Out-of-Phase (MOPTOP)}
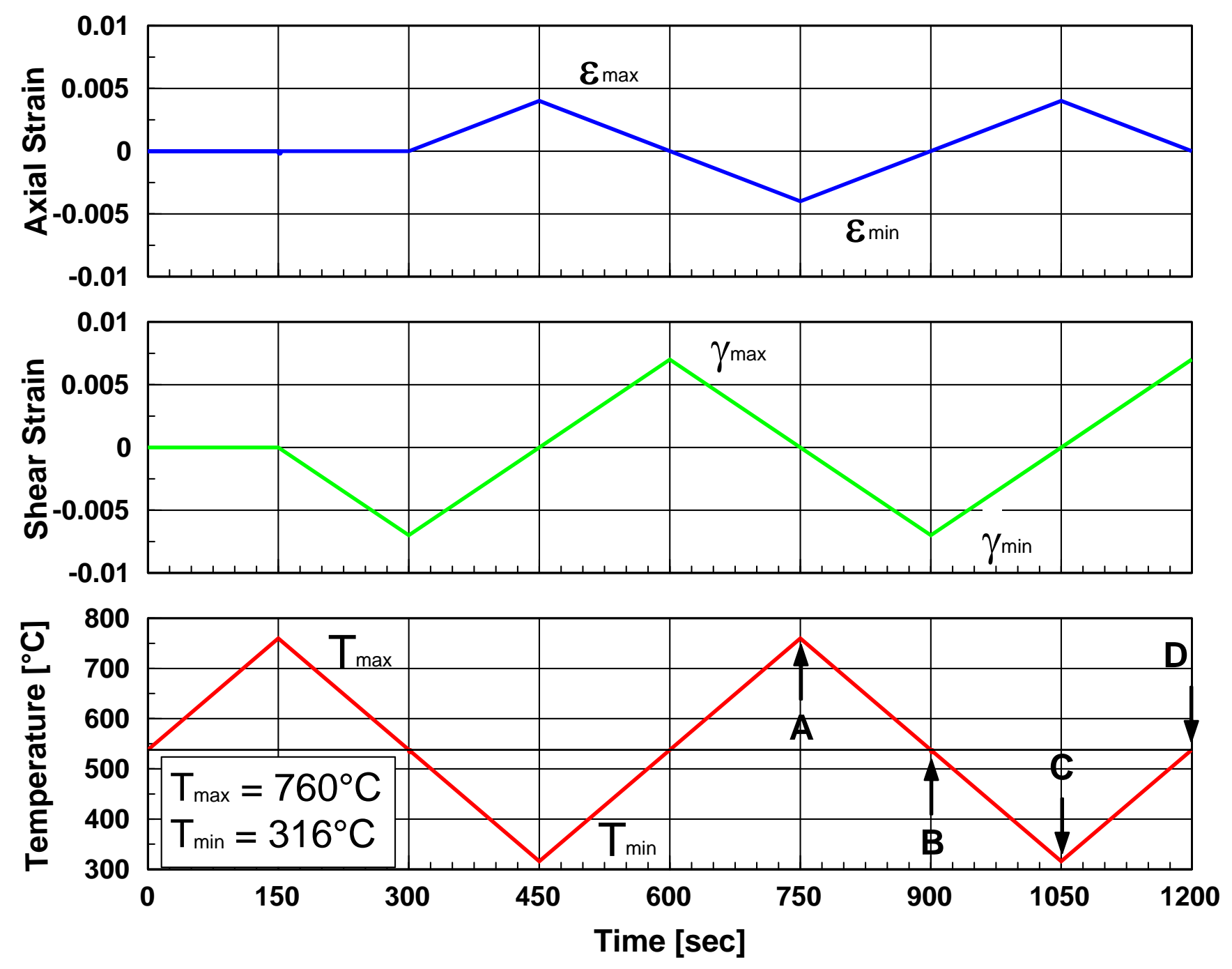


\section{Deformation Behavior in Mechanically In-Phase Axial-Torsional Fatigue Tests}

Axial Strain vs. Shear Strain

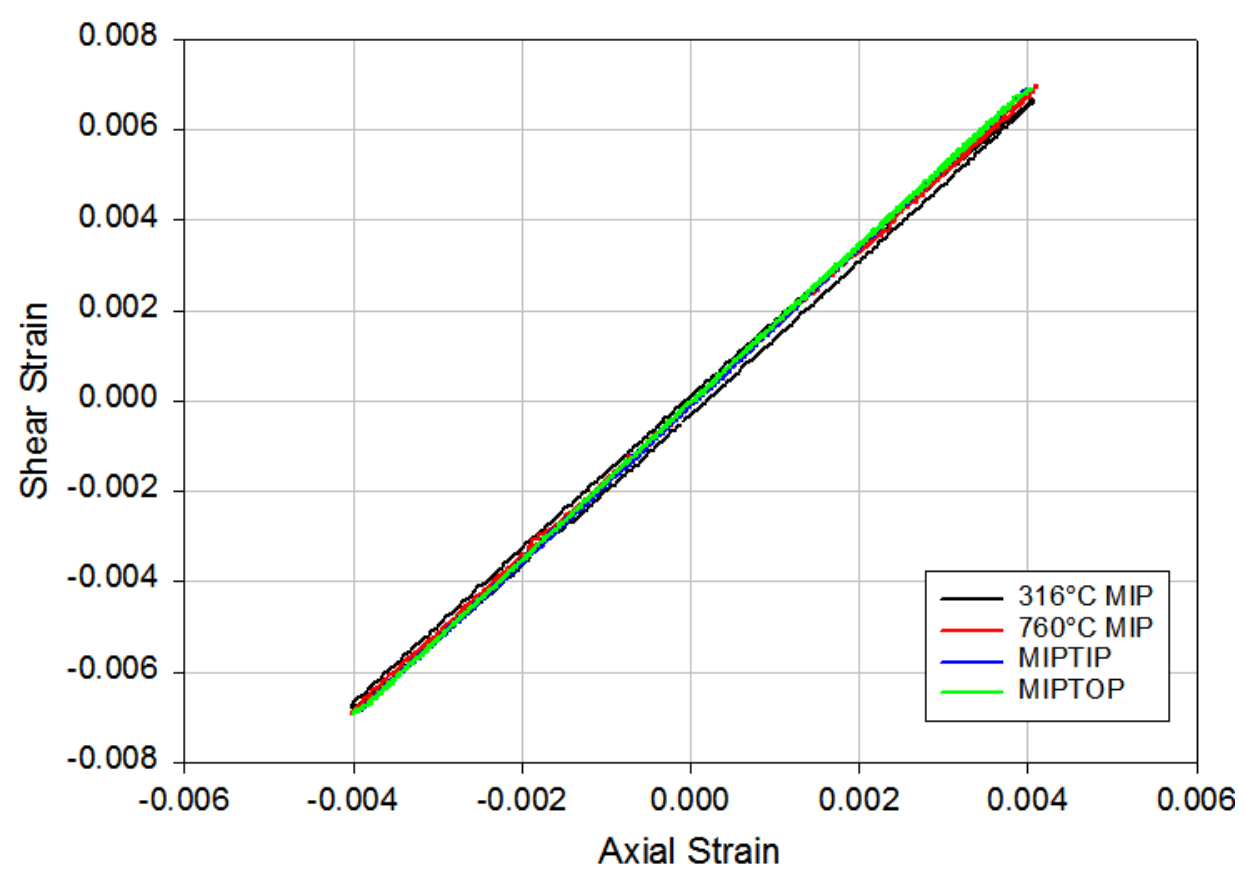

Axial Stress vs. Shear Stress

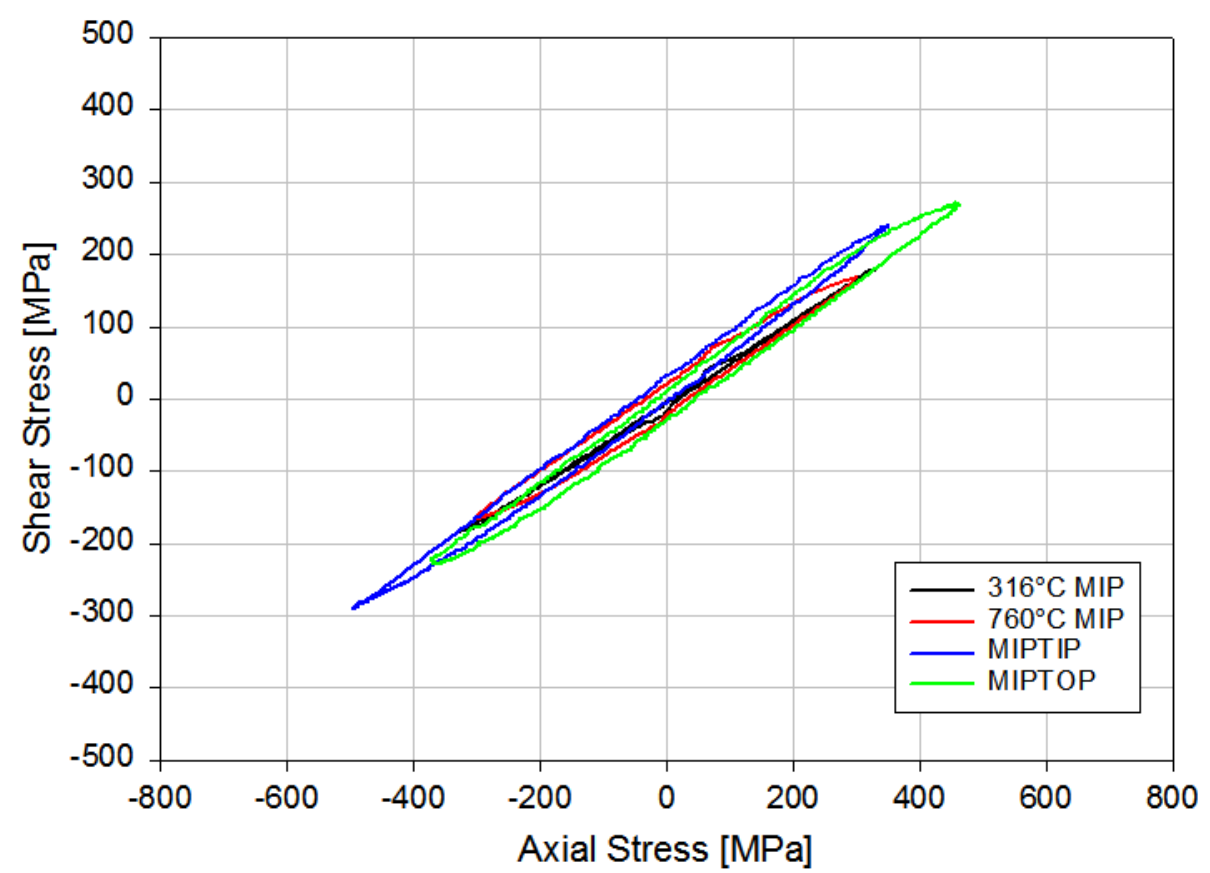

Reference: Bonacuse, P. J. and Kalluri, S., "Cyclic Deformation Behavior of Haynes 188 Superalloy Under Axial-Torsional, Thermomechanical Loading," Thermomechanical Fatigue Behavior of Materials: $4^{\text {th }}$ Volume, ASTM STP 1428, M. A. McGaw, S. Kalluri, J. Bressers, and S. D. Peteves, Eds., 2002. 


\section{Deformation Behavior in Mechanically Out-of-Phase Axial-Torsional Fatigue Tests}

Axial Strain vs. Shear Strain

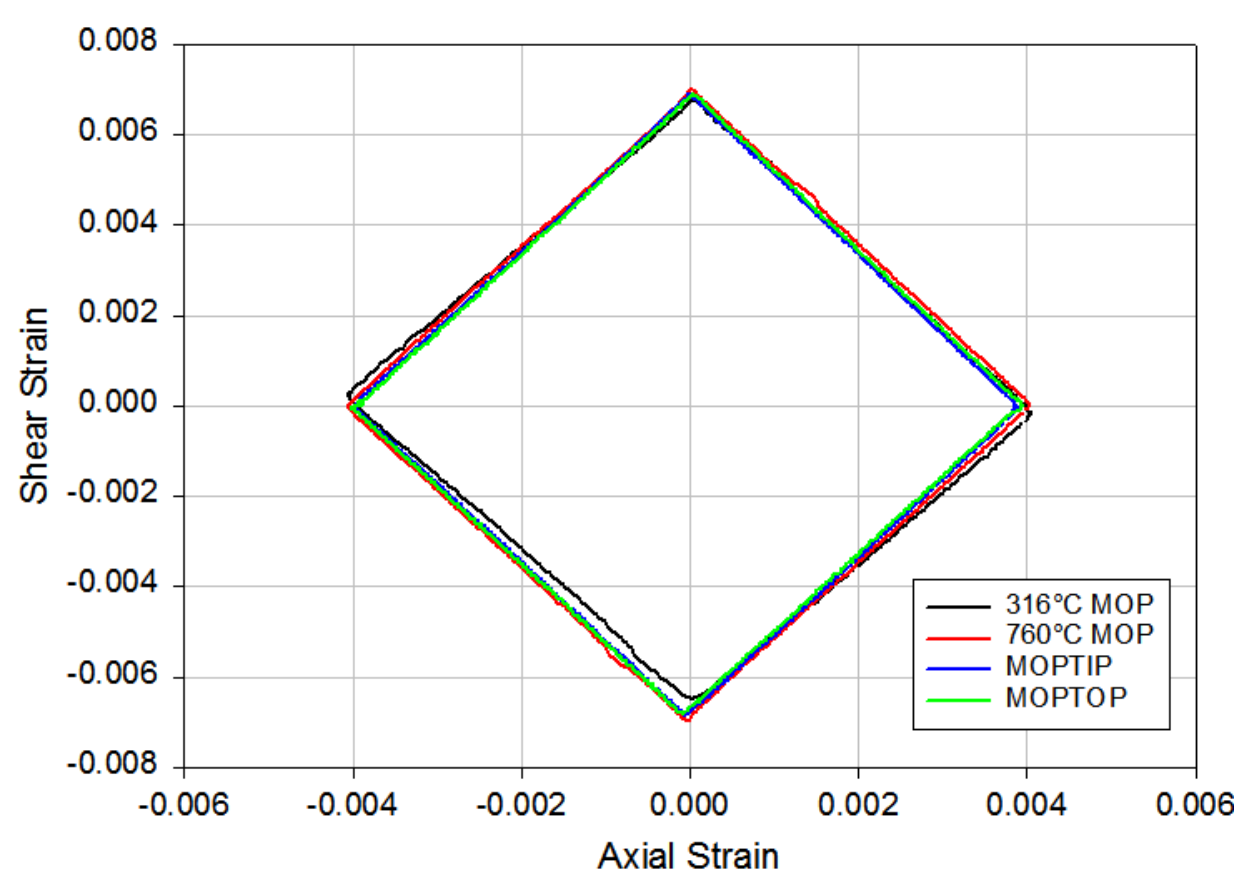

Axial Stress vs. Shear Stress

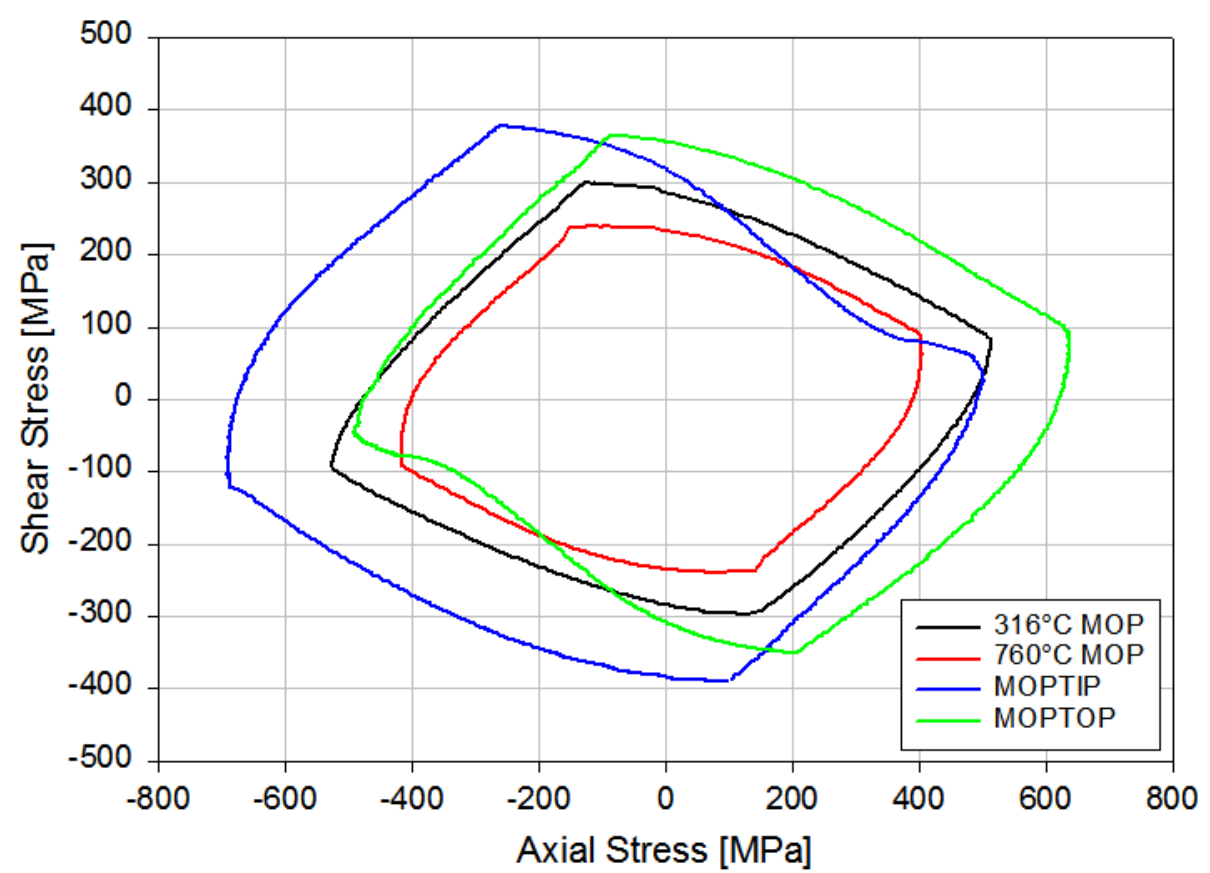

Reference: Bonacuse, P. J. and Kalluri, S., "Cyclic Deformation Behavior of Haynes 188 Superalloy Under Axial-Torsional, Thermomechanical Loading," Thermomechanical Fatigue Behavior of Materials: $4^{\text {th }}$ Volume, ASTM STP 1428, M. A. McGaw, S. Kalluri, J. Bressers, and S. D. Peteves, Eds., 2002. 


\section{Evolution of Maximum and Minimum Stresses in Mechanically Out-of-Phase Axial-Torsional Fatigue Tests}
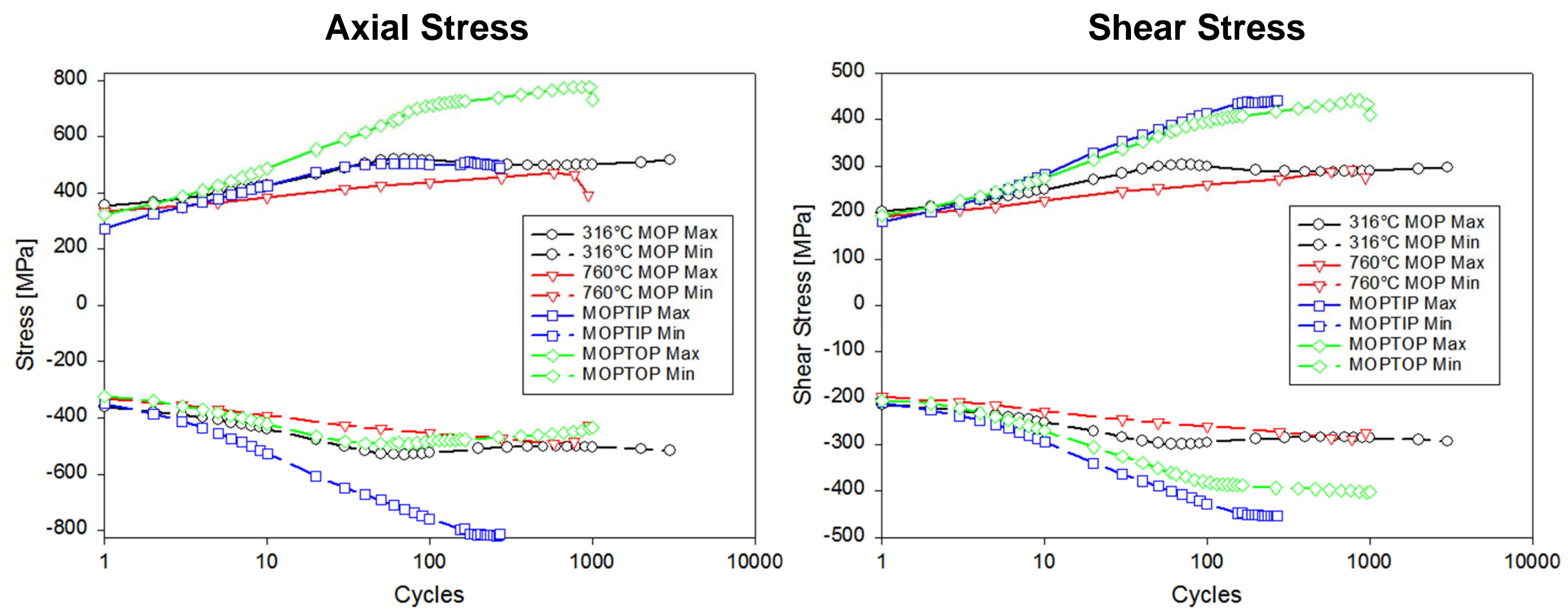

Reference: Bonacuse, P. J. and Kalluri, S., "Cyclic Deformation Behavior of Haynes 188 Superalloy Under Axial-Torsional, Thermomechanical Loading," Thermomechanical Fatigue Behavior of Materials: $4^{\text {th }}$ Volume, ASTM STP 1428, M. A. McGaw, S. Kalluri, J. Bressers, and S. D. Peteves, Eds., 2002. 


\section{Additional Hardening in Axial-Torsional Fatigue Tests}

\begin{tabular}{|c|c|c|c|c|c|}
\hline \multirow[b]{3}{*}{ Test 1} & \multirow[b]{3}{*}{ Test 2} & \multicolumn{2}{|c|}{ Axial } & \multicolumn{2}{|c|}{ Torsion } \\
\hline & & \multicolumn{2}{|c|}{$\Delta \sigma_{1}-\Delta \sigma_{2}[\mathrm{MPa}]$} & \multicolumn{2}{|c|}{$\Delta \tau_{1}-\Delta \tau_{2}[\mathrm{MPa}]$} \\
\hline & & $316^{\circ} \mathrm{C}$ & $760^{\circ} \mathrm{C}$ & $316^{\circ} \mathrm{C}$ & $760^{\circ} \mathrm{C}$ \\
\hline \multicolumn{6}{|c|}{ Additional Hardening from Out-of-Phase Mechanical Cycling } \\
\hline Isothermal MOP & Isothermal MIP & 328 & 242 & 202 & 167 \\
\hline \multicolumn{6}{|c|}{ Additional Hardening from Thermal Cycling } \\
\hline MIPTIP & Isothermal MIP & 202 & 224 & 194 & 199 \\
\hline MIPTOP & Isothermal MIP & 259 & 281 & 211 & 216 \\
\hline MOPTIP & Isothermal MOP & 279 & 387 & 299 & 339 \\
\hline MOPTOP & Isothermal MOP & 199 & 307 & 240 & 280 \\
\hline \multicolumn{6}{|c|}{ Additional Hardening from Combined Out-of-Phase Mechanical and Thermal Cycling } \\
\hline MOPTIP & Isothermal MIP & 607 & 629 & 501 & 506 \\
\hline MOPTOP & Isothermal MIP & 527 & 549 & 442 & 447 \\
\hline
\end{tabular}

Axial-Torsional TMF loading causes more hardening than Axial-Torsional isothermal loading 


\section{Additional Hardening in Axial-Torsional TMF Tests}

$760^{\circ} \mathrm{C}$ mechanically in-phase data used as baseline

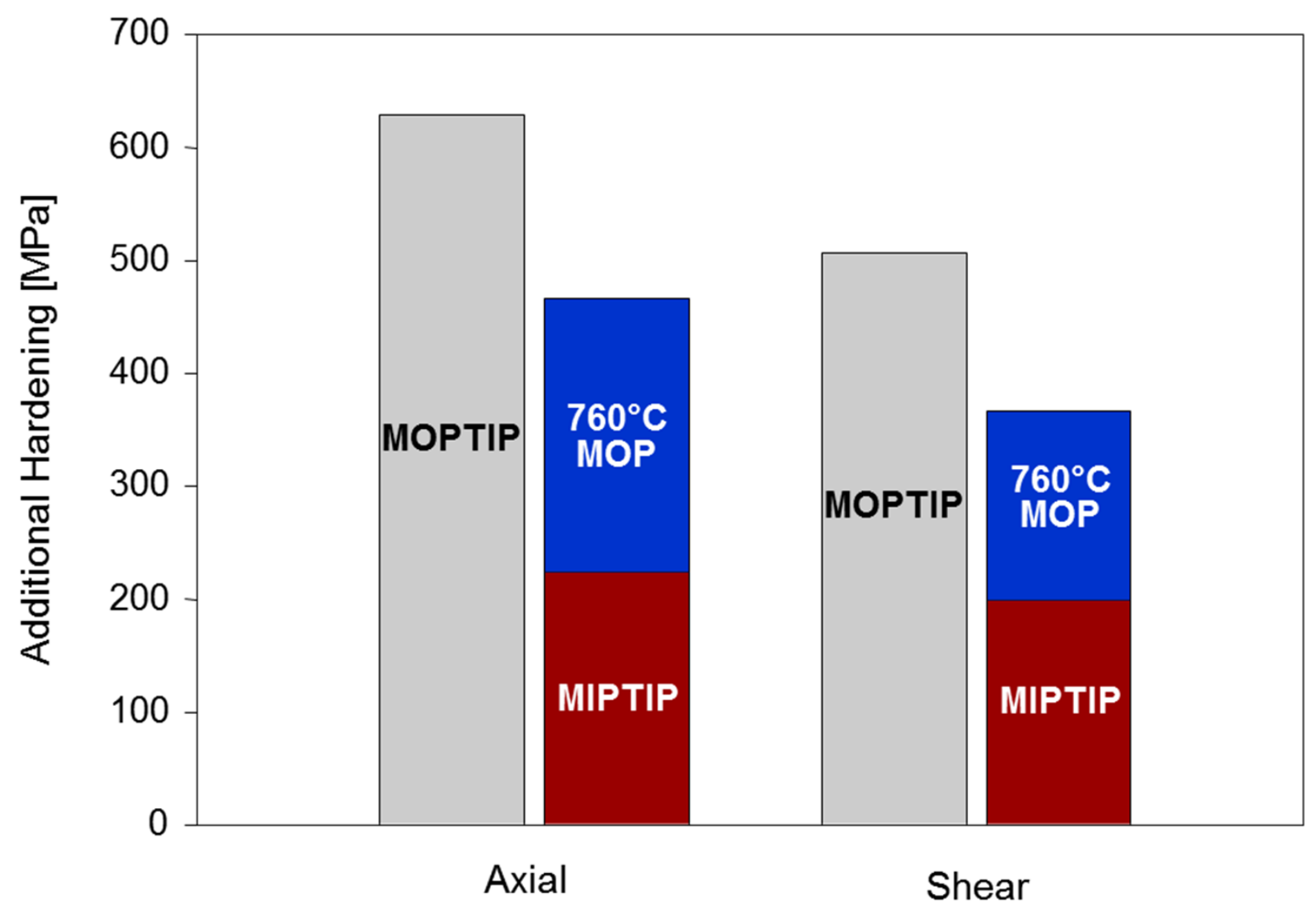

Reference: Bonacuse and Kalluri, ASTM STP 1428, 2002

Dissimilar mechanical and thermal phasings could synergistically interact to cause additional hardening 


\section{Axial-Torsional TMF Tests: Haynes $188\left(316\right.$ to $760^{\circ} \mathrm{C}$ )}

Fatigue Lives For Various Testing Conditions

$$
\Delta \varepsilon=0.008 \text { and } \Delta \gamma=0.014
$$
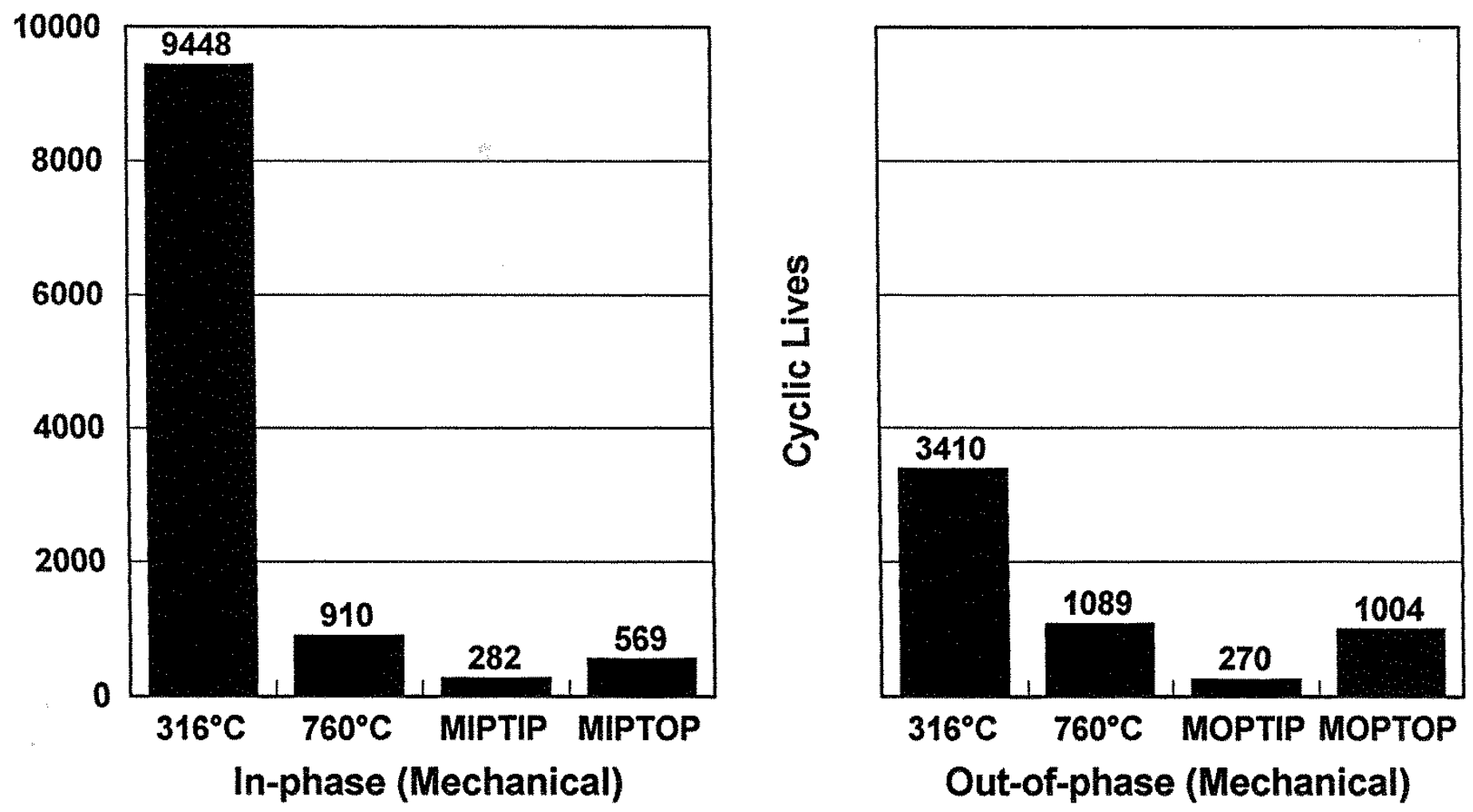

Thermally in-phase tests yielded lower cyclic lives regardless of the mechanical phasing 


\section{Multiaxial, Thermomechanical Fatigue -- Some Future Challenges}

- Cumulative fatigue under multiaxial, thermomechanical loads

- TMF under biaxial and equi-biaxial $(\lambda=1)$ loading conditions

- Determination of material's TMF behavior with specimens versus testing subcomponents of structures

- Influence of coatings on structural alloys

- Roles of residual stresses and environment

- Composites and functionally graded materials 
Cumulative Fatigue Example :

\section{Uniaxial TMF and Isothermal Fatigue}

HCF/LCF INTERACTION AT HIGH TEMPERATURE
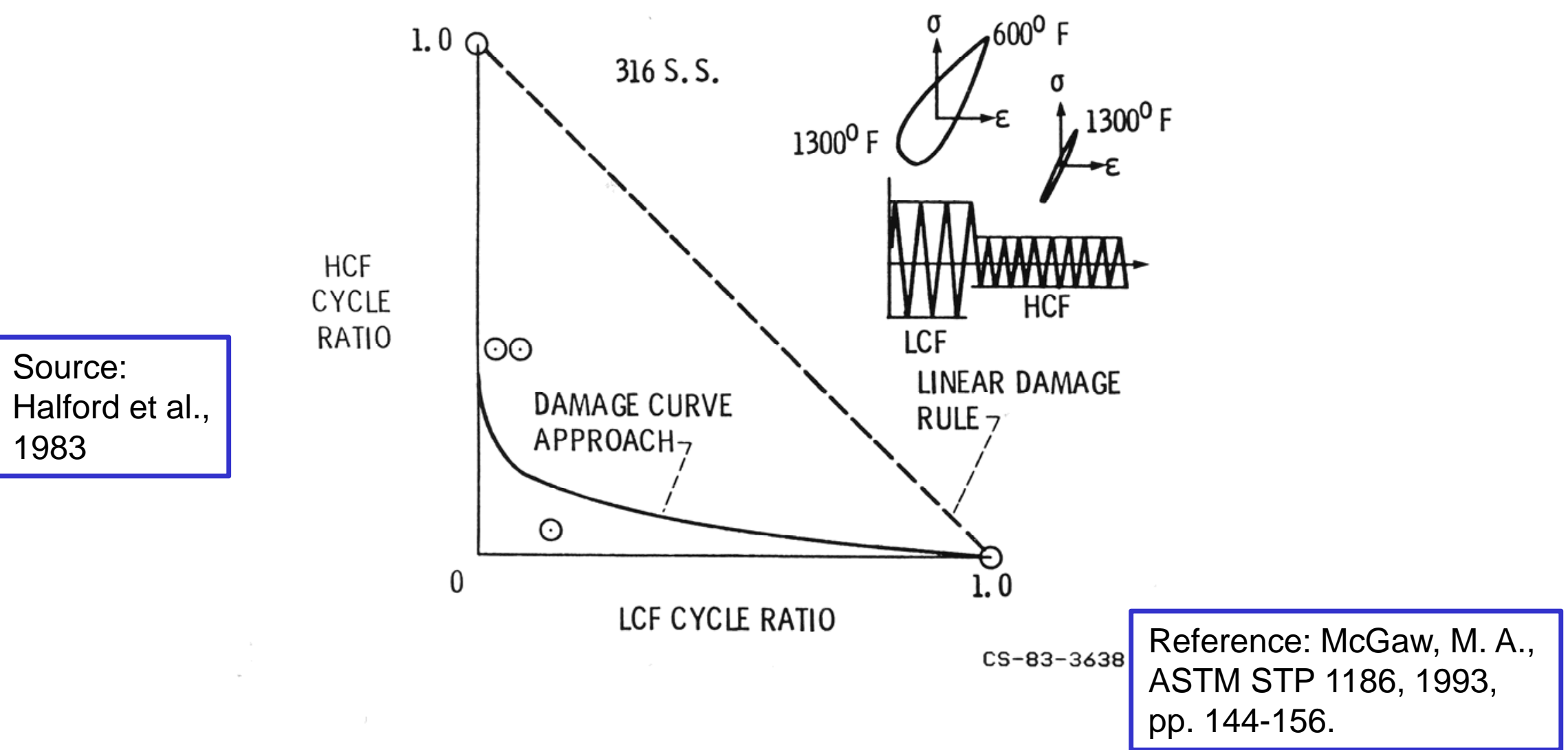

Cumulative fatigue behavior with out-of-phase TMF LCF and Isothermal HCF under uniaxial loading conditions 


\section{Multiaxial, Thermomechanical Fatigue -- Future Challenges}

- Thermomechanical fatigue under biaxial and equi-biaxial $(\lambda=1)$ loading conditions (thin-walled tubular specimens with internal/external pressure or cruiciform specimens)

- TMF system for testing cruciform specimens (Scholz, Samir, and Berger, Proc. of 7th Int. Conf. on Biaxial and Multiaxial Fatigue \& Fracture, Elsevier, 2004)

- Determination of material's TMF behavior with specimens versus testing subcomponents of structures (scale-up issues and reproducing service conditions)

- Test conditions are well defined and controlled for a chosen specimen design

- Tests involving subcomponents are more complex due to the difficulties involved in attaining required temperature profiles and imposing necessary multiaxial loads (design typically accomplished with analysis supplemented with limited testing for validation) 


\section{Multiaxial, Thermomechanical Fatigue -- Future Challenges}

- Influence of coatings (for example, thermal and environmental barrier coatings) on the multiaxial, TMF life of components

- LCF and HCF behavior of thick thermal barrier coatings investigated with a high power $\mathrm{CO}_{2}$ laser (Zhu and Miller, NASA TM-1998-206633)

- Thermal barrier coating / superalloy system tested multiaxial TMF (Bartsch et al., Int. J. of Fatigue, 2008); Thermal gradient mechanical fatigue tests on coated tubular specimens of IN 100 DS superalloy

- Roles of residual stresses and environment on the fatigue crack initiation under multiaxial, thermomechanical loads

- Depending upon the maximum temperature in the TMF cycle, any existing residual stresses may relax completely. However, at low maximum temperatures and small inelastic strains, residual stresses could influence fatigue life

- Oxidation plays a significant role and interacts with other damage mechanisms activated by multiaxial loads during TMF. Inert and vacuum environments could exhibit different damage modes under mutliaxial TMF. 


\section{Acknowledgements}

- Mechanical testing, analysis of results, and technical discussions

- Mr. Peter J. Bonacuse, Dr. Bradley A. Lerch, Mr. Christopher S. Burke, Dr. Michael A. McGaw, and Mr. Michael G. Castelli

- Steadfast Support and Encouragement

- Dr. Steven M. Arnold, Ms. Ann O. Heyward, Dr. Michael L. Heil, Mr. John R. Ellis (retired), and Late Mr. Marvin H. Hirschberg

- Mentorship

- Late Prof. S. S. Manson and Late Dr. Gary R. Halford

- Financial support provided by NASA Glenn Research Center Contract to USRA (NNC13TA85T; Task Number NNC13TA85T) and USRA Subcontract to OAI under Subtask NNC13TA85T-08 


\section{Mutiaxial Thermomechanical Fatigue (MTMF)}

Multiaxial Thermomechanical Fatigue (MTMF) can Induce Additional Cyclic Hardening and can Lower

Fatigue Life Significantly Compared to Uniaxial

Thermomechanical Fatigue and Isothermal

Multiaxial Fatigue!

MTMF should be Properly Evaluated in Designing and Lifing Engineering Components!! 